\title{
Impact of lateral groundwater flow on hydrothermal conditions of the active layer in a high arctic hillslope setting
}

\author{
Alexandra Hamm ${ }^{1,2}$ and Andrew Frampton ${ }^{1,2}$ \\ ${ }^{1}$ Department of Physical Geography, Stockholm University, Stockholm, Sweden \\ ${ }^{2}$ Bolin Centre for Climate Research, Stockholm University, Stockholm, Sweden
}

Correspondence: Alexandra Hamm (alexandra.hamm@natgeo.su.se)

\begin{abstract}
Modeling the physical state of permafrost landscapes is a crucial addition to field observations in order to understand its feedback mechanisms within a warming climate. A common hypothesis in permafrost modeling is that vertical heat conduction is most relevant to derive subsurface temperatures. While this approach is mostly applicable to flat landscapes with little topography, landscapes with more topography are subject to lateral flow process as well. With our study, we want to contribute to the growing body of evidence that lateral surface- and subsurface processes can have a significant impact on permafrost temperatures and active layer properties. We use a numerical model to simulated two idealized hillslopes with inclinations that can be found in Adventdalen, Svalbard, and compare them to a flat control case. We find that ground temperatures within the active layer uphill are generally warmer than downhill in both slopes (up to $1.2^{\circ} \mathrm{C}$ in the steep, and $0.7^{\circ} \mathrm{C}$ in the medium slope). Further, the slopes are found to be warmer in the uphill section and colder in the very bottom of the slopes compared to the flat control case. As a result, maximum thaw depth increases by about $5 \mathrm{~cm}$ from the flat $(75 \mathrm{~cm})$ to the steep slope $(80 \mathrm{~cm})$, while the medium case does not exhibit a deepening in thaw depth $(75 \mathrm{~cm})$. Uphill warming on the slopes is explained by additional energy gain through infiltration and lower evaporation rates due to a overall drier environment. The major governing process causing the cooling on the downslope side is heat loss to the atmosphere through evaporation in summer and enhanced heat loss in winter due to wetter conditions and resulting higher thermal conductivity. On a catchment scale, these results suggest that temperature distributions in hilly terrain can vary considerably compared to flat terrain, which might change the response of subsurface hydrothermal conditions to ongoing climate change.
\end{abstract}

\section{Introduction}

Permafrost is defined as ground that remains below $0{ }^{\circ} \mathrm{C}$ for at least two consecutive years. It covers approximately $24 \%$ of the exposed land area in the northern hemisphere (Zhang et al., 1999) and stores about $1030 \mathrm{Pg}$ of organic carbon in the upper 3 meters of soil (Hugelius et al., 2014). With increasing air temperatures in the Arctic, this carbon stock gets thawed out of the permafrost, exposing it to microbial decomposition and displacement. How much carbon gets released from the permafrost is strongly influenced by the depth of the active layer, the part of the soil that seasonally thaws out (e.g., Biskaborn et al., 2019). The correlation between increasing air temperature and depth of the active layer is well established (e.g., Zhang et al., 1997; Isaksen et al., 2007; Frauenfeld et al., 2004). Especially high summer temperatures in dry environments have a direct impact on 
https://doi.org/10.5194/tc-2021-60

Preprint. Discussion started: 7 April 2021

(c) Author(s) 2021. CC BY 4.0 License.

\section{(c) (i)}

the development of the active layer in the same year (Isaksen et al., 2007). However, the effect of precipitation and hydrology in the active layer are less well understood as their effects are more dynamic and non-linear (e.g., Wen et al., 2014). Due to the water impermeability of frozen ground, relevant hydrological processes are limited to the active layer. With increasing active layer thicknesses, more water can infiltrate into the ground and move laterally. The degradation of permafrost has found to decrease the seasonal variability of groundwater discharge into surface waters, changing the hydraulic connectivity in the subsurface and potentially also the solute transport capabilities (Frampton et al., 2011, 2013; Evans and Ge, 2017; McKenzie et al., 2021). Further, higher moisture abundance in the active layer can not only regulate the decomposition of organic carbon (e.g., McGuire et al., 2009; Koven et al., 2011) but can also affect infrastructure built on the fragile frozen ground (e.g., de Grandpré et al., 2012) or change the thermal properties of the permafrost (e.g., Schuh et al., 2017). Therefore, it is important to investigate the effect of hydrology in permafrost landscapes.

In general, it is known that the amount of liquid water in the soil has a direct effect on its thermal properties (e.g., Iijima et al., 2010; Zhu et al., 2017). Higher saturated soils are expected to conduct more heat towards the subsurface than drier soils in summer and, depending on the insulating effect of the snow cover, loose energy to the atmosphere in winter (Kane et al., 2001). These conclusion are often based on $1 \mathrm{D}$ representations of permafrost soils due to the assumption that vertical heat conduction is the major control of energy fluxes. For flat landscapes with little topography and low hydraulic gradients, these assumptions might be sufficient (Westermann et al., 2016; Langford et al., 2020). However, for permafrost underlying slopes and landscapes with more topography, vertical conduction alone is not able to explain permafrost degradation and seasonal active layer thaw. Due to the slopes and hydraulic gradients, lateral advection of water and energy might change the ground temperature between the up- and downhill location. Especially in warmer, discontinuous permafrost landscapes, heat carried laterally by water has proven to be essential for subsurface temperatures and permafrost thaw (Sjöberg et al., 2016; Kurylyk et al., 2016; de Grandpré et al., 2012). This effect is even more enhanced and prolonged if water is gathering in water tracks on hillslopes (Evans et al., 2020). In a controlled laboratory experiment it was also found that subsurface flow can greatly enhance active layer thaw, but highly depends on the water temperature (Veuille et al., 2015). Further, Groundwater flow along a hillslope in combination with preferential snow accumulation has shown how water and heat transport affect the emergence of a talik and how the talik can change the hydrological pathways within a permafrost hillslope (Jafarov et al., 2018).

In high Arctic continuous permafrost landscapes, the effect of subsurface flow is expected to be less strong due to thin organic layers and generally low hydraulic conductivities (Loranty et al., 2018). In Yukon, Canada, it has been observed that vertical heat advection through snow-melt and summer rain infiltration on a road embankment change subsurface temperatures faster than through heat conduction from the surface (Chen et al., 2020).

In this study, we investigate the role of hydrology on two high Arctic hillslopes and its effects on the active layer and ground temperatures, using a physically-based numerical model. Understanding and quantifying local-scale hydraulic permafrost processes helps to better constrain and inform global climate models and the feedback mechanisms between permafrost landscapes and the atmosphere, as permafrost is a key component of the climate system (Riseborough et al., 2008; Schuur et al., 2015). While field measurements are a vital source to achieve this, numerical modeling allows for applications in more remote and less accessible areas. 
https://doi.org/10.5194/tc-2021-60

Preprint. Discussion started: 7 April 2021

(c) Author(s) 2021. CC BY 4.0 License.

\section{(c) (i)}

We conducted a series of numerical model investigations representing typical hillslope environments and hydro-meteorological conditions of Adventdalen, Svalbard. Svalbard is located at $78^{\circ} \mathrm{N}$ and $15^{\circ} \mathrm{E}$ and therefore represents high-Arctic climate. Active layer thickness in Adventdalen has shown to increase with a rate of $0.7 \mathrm{~cm} \mathrm{yr}^{-1}$ over the last decades (Strand et al., 2020). The location of Adventdalen in close vicinity to Svalbard's main settlement Longyearbyen further paves the way to validate model results with field measurements due to relatively easy access. The hillslopes are represented as idealized slopes with a steep $\left(22^{\circ}\right)$ and medium $\left(11^{\circ}\right)$ inclination and are compared to a reference case without inclination (flat case). We focus on absolute temperature differences between the uphill and downhill side in the slopes at several different depths within the active layer as well as the transect-wide active layer thickness in all cases.

The model is controlled and driven by site-specific hydro-meteorological data and subsurface properties. The data represents current climatic conditions in Svalbard. Our objectives are to understand and quantify the effects hillslope inclination have on active layer thermal and hydraulic dynamics of a permafrost catchment.

Specifically, the following questions are investigated: (i) To which extent does hillslope inclination affect the ground temperatures in a permafrost catchment? (ii) Tho which extent is maximum active layer thickness and the volume of unfrozen soil affected by those differences? (iii) Which processes are responsible for the differences?

\section{Data and method}

The focus of this study is to investigate the effects that subsurface flow has on ground temperature and moisture in the active layer of a hillslope system located in a continuous permafrost environment. For this problem, the main governing processes which are relevant to consider are surface energy balances stemming from solar radiation, thermal insulation due to snow cover, sources of precipitation (snow, rain) with associated snow and/or ice accumulation, surface ponding and runoff on frozen or saturated ground, surface-subsurface infiltration in thawed and unsaturated ground, and subsurface water flow and heat transport in partially saturated, partially frozen ground. These processes are intricately coupled, in essence because water flow both above and below ground carries energy as a form of advective heat transport, and heat transport impacts the phase state of water, as liquid, ice or vapour, which in turn exerts control on water flow and heat conduction.

A numerical model is configured to correspond to site-specific conditions representative of hillslopes in Adventdalen, Svalbard, which is driven by atmospheric forcing and landscape data measured on-site. The model used is the Advanced Terrestrial Simulator (ATS v0.88, Coon et al., 2019). ATS is an open source, physically-based numerical model for coupled surface/subsurface thermal hydrology, specifically adopted for cold regions and permafrost applications (Painter et al., 2016).

A brief summary of the governing processes follows; for a full description see the cited references. ATS solves coupled conservation equations for energy and water mass transport, considering both above and below ground processes, based on a multiphysics framework (Coon et al., 2016). (Painter, 2011) The available energy at the surface-subsurface interface drives subsurface heat transport, and is obtained by solving for a surface energy balance equation (Atchley et al., 2015). Snow and ice on the surface affect heat conduction by reducing or increasing thermal conductivity, and subsequently impact heat transfer 
https://doi.org/10.5194/tc-2021-60

Preprint. Discussion started: 7 April 2021

(c) Author(s) 2021. CC BY 4.0 License.

(c) (i)

to the subsurface. Snow and ice are also subject to melting and ponding and can provide a source of water infiltration and/or surface runoff. Unfrozen water flow on the surface follows the Manning equation Painter et al. (2016).

In the subsurface, conductive heat transport follows Fourier's law, with an effective thermal conductivity based on the material properties and accounting for the phase state of the pore-filling fluid (as ice, liquid or air) (Painter, 2011). Advective heat transport occurs as heat carried by water movement in the porous media. Subsurface flow of water is governed by the extended Darcy law for partially saturated flow, where phase transitions follow the Clausius-Clapeyron relationship accounting for latent heat transfer. Soil moisture retention curves, adopting a van Genuchten formulation, are used to describe effective permeability in the variably saturated pore space, accounting for the presence of air and ice, where ice is considered an immobile phase, causing a reduction in available porosity (Painter and Karra, 2014). Furthermore, ATS adopts a flux-conserving finite volume solution scheme and supports unstructured meshes, thus can conveniently be used for applications in $1 \mathrm{D}, 2 \mathrm{D}$ and $3 \mathrm{D}$, accounting for vertical and lateral processes in all dimensions considered.

\subsection{Field data}

The observational weather data to drive the model (hereinafter referred to as the forcing dataset) is derived from a automatic weather station located in Adventdalen $\left(78.2^{\circ} \mathrm{N} 15.87^{\circ} \mathrm{E}\right)$. The station is operated by the University Center in Svalbard and captures all data needed for the daily surface energy balance, except for precipitation, in the time from 2013 to 2019 . Precipitation data was retrieved from the long-term weather station at Longyearbyen airport $\left(78.24^{\circ} \mathrm{N} 15.51^{\circ} \mathrm{E}\right)$ operated by the Norwegian Meteorological Institute. Mean values for every day of the year (day-of-year average) between 2013 and 2019 were calculated to represent current average weather conditions. Further data processing involved the classification of precipitation as rain if mean daily air temperatures were above $0^{\circ} \mathrm{C}$ and as snow if air temperatures were below $0^{\circ} \mathrm{C}$. An adjustment for precipitation undercatch in Svalbard has been suggested to be 1.85 for snow and 1.15 for rain (Førland and Hanssen-Bauer, 2000). Precipitation is multiplied by these factors. The resulting sum of rain $(160 \mathrm{~mm})$ and snow $(170 \mathrm{~mm}$ w.e., total precipitation $=330 \mathrm{~mm}$ ) was then redistributed to equal daily amounts during the rain- and snow period, respectively. The mean annual air temperature for the calculated averages is $-2.8^{\circ} \mathrm{C}$. A representation of all variables within the forcing dataset can be found in the supplementary material (Fig. S1). To inform the model, the same forcing dataset is used for the entire model domain without accounting for temperature lapse rates between the lower and upper part of the transect.

\subsection{Simulation configurations}

Three model cases are considered; a steep case a steep case with $22^{\circ}$ inclination, a moderate case with $11^{\circ}$ inclination, and a flat case with $0^{\circ}$ inclination. The flat case is used primarily as reference to evaluate effects of inclination and to normalise quantities for analysis. The model cases are identical in all respects other than inclination. Note that the elevation difference between the uppermost and lowermost part of the slopes is 10 and $20 \mathrm{~m}$ for the medium and steep slope, respectively, but temperature does not change depending on altitude in this setup.

The inclinations are based on slopes as they can be found in Adventdalen and its southern tributaries mostly below $200 \mathrm{~m}$ elevation. Geologically, the slopes are located within the Carolinefjellet formation, which mainly consists of shale, siltstone 
https://doi.org/10.5194/tc-2021-60

Preprint. Discussion started: 7 April 2021

(c) Author(s) 2021. CC BY 4.0 License.

Table 1. Physical properties of the subsurface material. Notations $S_{\text {uf }}$ and $D_{\text {uf }}$ denote saturated, unfrozen and dry, unfrozen conditions.

\begin{tabular}{llr}
\hline Material Property & Unit & Value \\
\hline Porosity & $\mathrm{m}^{3} \mathrm{~m}^{-3}$ & 0.4 \\
Permeability & $\mathrm{m}^{2}$ & $2 \times 10^{-13}$ \\
Density & $\mathrm{kg} \mathrm{m}^{-3}$ & 2650 \\
Van Genuchten $\alpha$ & $\mathrm{Pa}^{-1}$ & $8 \times 10^{-4}$ \\
Van Genuchten $m$ & - & 0.2 \\
Thermal conductivity $S_{\text {uf }}$ & $\mathrm{W} \mathrm{m}^{-1} \mathrm{~K}^{-1}$ & 1 \\
Thermal conductivity $D_{\mathrm{uf}}$ & $\mathrm{W} \mathrm{m}^{-1} \mathrm{~K}^{-1}$ & 0.29 \\
Specific heat capacity & $\mathrm{J} \mathrm{kg}^{-1} \mathrm{~K}^{-1}$ & 850 \\
\hline
\end{tabular}

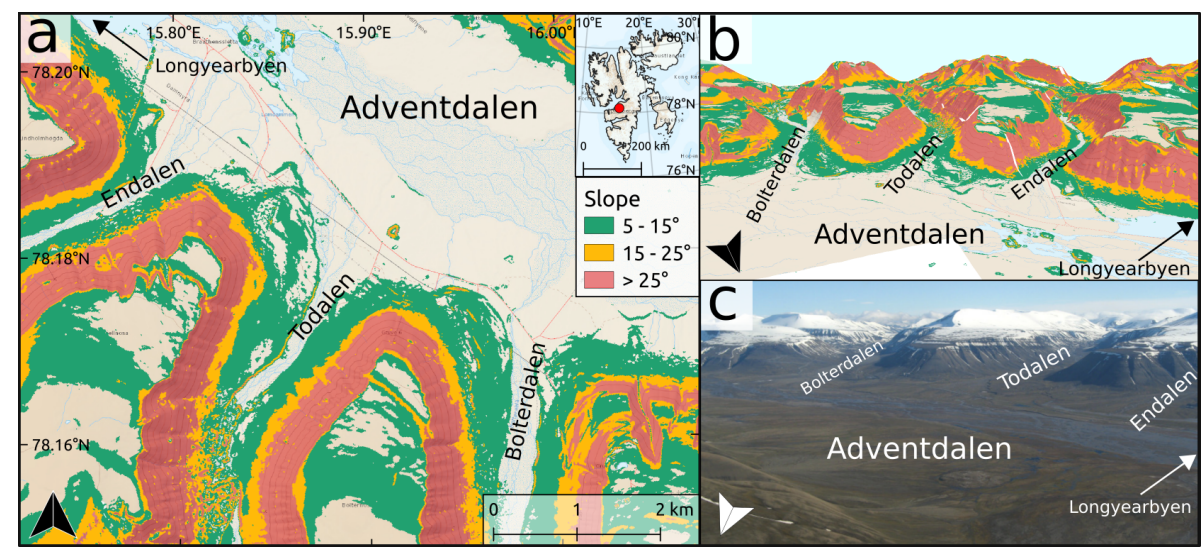

Figure 1. Overview over the general study area. (a) Map with slope inclinations greater than $10^{\circ}$ along some of Adventdalen's southern tributaries (Endalen, Todalen, Bolterdalen). (b) 3D view of the valleys and slope of the map in panel (a). Basemap data has been retrieved from the Norwegian polar institute. Inclination values are based on elevations from the Arctic DEM (10 m resolution; Porter et al., 2018). (c) Areal image of Adventdalen overlooking the same area as in the maps in panels (a) and (b). The picture was taken from a helicopter by A. Skosgslund (Norwegian polar institute).

and sandstone. All hillslope areas greater than $10^{\circ}$ inclination in the area of question are shown in Fig. 1. The flat control case corresponds to areas with no considerable inclination as they can be found in the valley bottom in Adventdalen. These areas are characterized by holocene glaci-fluvial deposits (Norwegian polar institute).

Each model case has a corresponding surface and subsurface mesh. The surface mesh is a 2D layer which extends $50 \mathrm{~m}$ in $x$-direction and $1 \mathrm{~m}$ in $y$-direction, and the subsurface mesh extends $50 \mathrm{~m}$ in $x$-direction, $1 \mathrm{~m}$ in $y$-direction and $20 \mathrm{~m}$ in the $z$-direction (Fig. 2). Both have a lateral resolution of $2 \mathrm{~m}$ yielding 25 mesh elements along the $x$-direction. Only one element with unit width is assigned in the transverse $y$-direction. Thus, the subsurface elements are 3D volumes and yield volumetric flow quantities, but the model setup effectively represents a 2D transect of the surface-subsurface system with unit width. In 


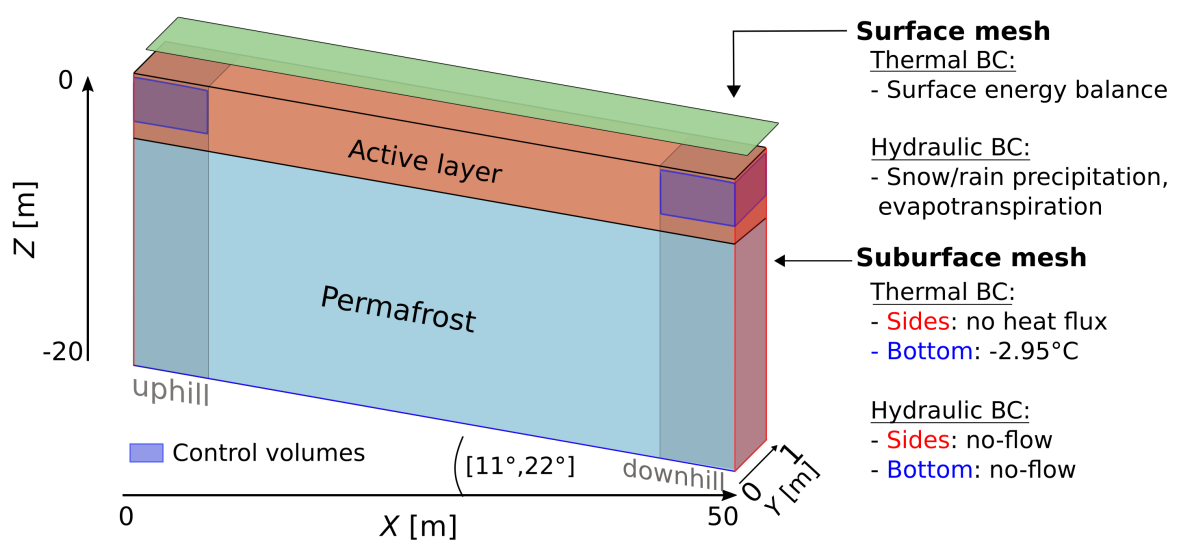

Figure 2. Conceptual representation of the surface and subsurface modeling domain. Shaded areas on either side of the transect indicate the uphill and downhill observation locations, red indicates the sides of the model, blue boxes represent the control volumes (CV) and a blue line at the bottom indicates the bottom boundary. Thermal-hydraulic boundary conditions (BC) on the surface, sides and bottom are listed on the right.

the uppermost meter of each column, cells are generated with a higher resolution of $0.05 \mathrm{~m}$ height in the vertical direction, in order to improve the spatial resolution of the active layer. With increasing depth, cell thickness gradually increases.

The downhill end of the transect represents the valley bottom, and allows for water accumulation and potential ponding on the surface. All cases assume a homogeneous material consistent with mineral soils typically encountered in the area. The physical and material properties used to describe the subsurface domain (Table 1) are consistent with a previous study based on the UNISCALM site in Adventdalen $\left(78.2^{\circ} \mathrm{N} 15.75^{\circ} \mathrm{E}\right)$ (Schuh et al., 2017).

Figure 2 depicts the model domain and the respective defined points and faces of interest. The domain-boundaries in the subsurface are prescribed as no-flow boundaries on the right, left and bottom. The bottom temperature is set to $-2.95^{\circ} \mathrm{C}$, which has found to be the temperature at $19 \mathrm{~m}$ depth in a borehole in Endalen, one of Adventdalen's tributaries (Hanssen-Bauer et al., 2018). The borehole is located on a slope and therefore assumed to be representative for other slopes in Adventdalen. As the borehole temperature experiences a linear increasing trend throughout the 2013-2019 period, the mean value of the same period is used. The surface is subject to hydro-meteorological conditions measured on-site (the forcing dataset), which effectively drives the dynamics of heat and water flow through the model system. Precipitation is added as snow and rain on the surface, which allows for infiltration, and heat is supplied by the surface energy balance. Water can leave the system via evapotranspiration and the surface allows for snow and ice accumulation as well as water ponding. Snow distribution is intentionally disabled, in order to yield the same snow accumulation on the surface of the model domain.

The model output is given as field values in selected locations. Analysis of field values includes temperature, saturation and thermal conductivity, extracted at $0.1 \mathrm{~m}, 0.2 \mathrm{~m}, 0.4 \mathrm{~m}$ and $0.75 \mathrm{~m}$ depth at an uphill and downhill location of each model domain. These depths are chosen as they represent the near-surface soil conditions, the middle of the active layer and the bottom of the active layer. Temperature differences over the entire transect are extracted for specific points in time. 
https://doi.org/10.5194/tc-2021-60

Preprint. Discussion started: 7 April 2021

(c) Author(s) 2021. CC BY 4.0 License.

\section{(c) (i)}

For analysis of fluxes, two control volumes (CV) are defined, also located uphill and downhill (see Fig. 2). The uphill CV extends from 0 to $2 \mathrm{~m}$ in $x$-direction, 0 to $1 \mathrm{~m}$ in $y$-direction, and from 0.1 to $0.6 \mathrm{~m}$ in $z$-direction. The volume of the box is thus approximately $\sim 1 \mathrm{~m}^{3}$. The downhill $\mathrm{CV}$ is defined as a box from 48 to $50 \mathrm{~m}$ in $x$-direction, 0 to $1 \mathrm{~m}$ in $y$-direction, and 0.1 to $0.6 \mathrm{~m}$ in $z$-direction $\left(\sim 1 \mathrm{~m}^{3}\right)$. Since the left and right boundary are no-flow boundaries, lateral fluxes in the CVs are only represented on the right boundary of the uphill CV and on the left boundary of the downhill CV. We placed the CVs at these locations to capture the most extreme values within the domain and to link them to the cell values in the first and last column. The upper boundary is moved $0.1 \mathrm{~m}$ below the surface, as the surface itself includes more processes than subsurface faces, which would complicate the comparison to the bottom-boundary face of the CV. Each face of the box is used to capture advected and diffusive energy flux, and mass flux into and out of the domain during the simulation.

Model initialisation and spin-up is conducted with a 3-step procedure following previously established routines for permafrosthydrological modelling (Frampton et al., 2013; Karra et al., 2014; Painter et al., 2016). First, a single 1D column is used to establish hydrostatic conditions with the water table at a target depth, using pressure boundary conditions for the top and bottom faces of the model. Second, the soil and water in the column is cooled from below with an assigned sub-zero bottom temperature, until the column is fully frozen and reaches a cryotic steady-state. In the third step, the forcing dataset is used to bring the thermal hydraulic conditions of the column model into an annual steady state. The day-of-year average yearly cycle created from the weather data is repeated for 50 years to create the forcing dataset. After 50 years, this yields an inter-annual temperature differences throughout the column of less than $0.01^{\circ} \mathrm{C}$.

This above procedure is necessary to obtain a physically consistent system which can be used as initial condition for main simulation runs. The resulting state from this $1 \mathrm{D}$ single column spinup model is mapped to each of the 25 columns of the hillslope transect model. Thereafter, the main model runs are conducted by using the forcing dataset once again, this time allowing for all lateral and vertical dynamic processes.

This final fourth step is run for 100 years, until an annually periodic steady-state for the full surface-subsurface hillslope models is obtained. This results in a representation of the hydrothermal state of the subsurface corresponding to the current 2013-2019 average weather conditions. The process is repeated for each of the three model inclination cases to ensure effects of hillslope inclination are embedded in the final model results.

\section{Results and discussion}

\subsection{Temporal analysis of ground temperatures}

Daily ground temperatures in the active layer $(0.1 \mathrm{~m}, 0.2 \mathrm{~m}$ and $0.4 \mathrm{~m}$ depth) and near the permafrost table ( $0.75 \mathrm{~m}$ depth) vary between the different inclination cases, and there are also temperature differences between the uphill and downhill observation locations. Additionally, timing of thaw and freeze-up varies between cases. To enable a systematic study of the impact of the different hillslope inclinations, we consider daily temperature differences $\Delta \mathrm{T}_{\mathrm{I}}$ between the steep slope and flat case (steep-flat), as well as between the medium slope and flat case (medium-flat). We also consider daily temperature differences $\Delta \mathrm{T}_{\mathrm{E}}$ between uphill and downhill observation points (uphill-downhill), corresponding to different elevations along a hillslope (Fig. 3). 
https://doi.org/10.5194/tc-2021-60

Preprint. Discussion started: 7 April 2021

(c) Author(s) 2021. CC BY 4.0 License.

(c) (i)

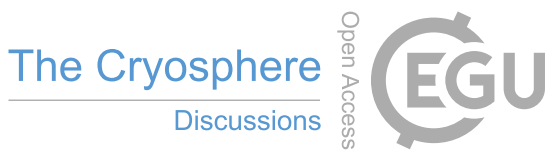
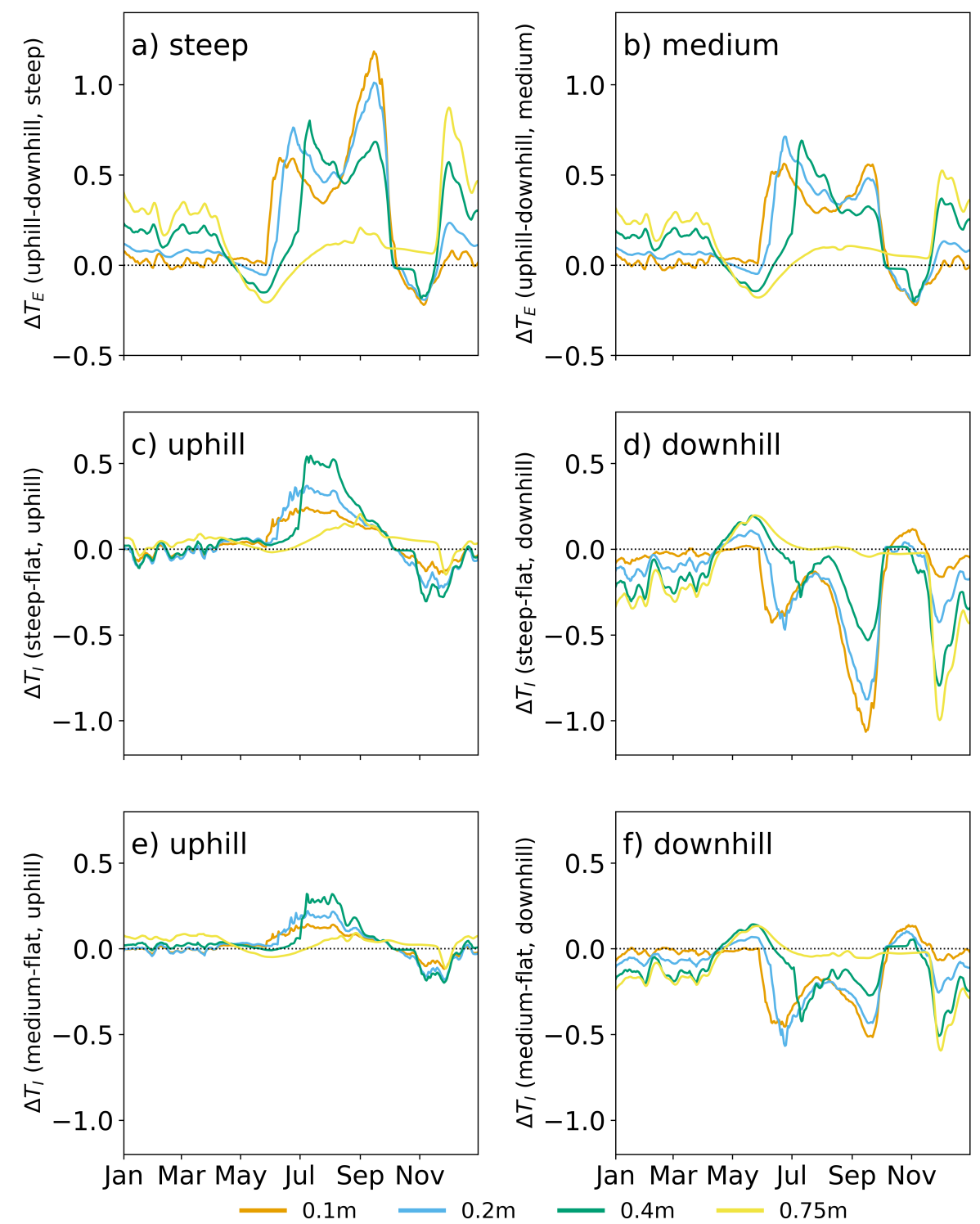

Figure 3. Daily temperature differences (averaged over a 7-day window) $\Delta \mathrm{T}_{\mathrm{E}}(\mathbf{a}, \mathbf{b})$ and $\Delta \mathrm{T}_{\mathrm{I}}(\mathbf{c}, \mathbf{d}, \mathbf{e}, \mathbf{f})$ in four different depths within the active layer.

There is significant variability in these temperature differences over the year, with most pronounced differences occurring during the warm season, typically including a peak at onset of thaw and another peak before freeze-up, indicating greatest differences occurring during these times. Between the uphill and downhill side in the steep and medium slope (Figures 3a,b), it can be seen that the uphill side is warmer than the downhill side throughout the year (positive $\Delta \mathrm{T}_{\mathrm{E}}$ ), with two short exceptions during thaw and freeze-up (negative $\Delta \mathrm{T}_{\mathrm{E}}$ ). The warming is strongest in summer with two peaks developing just after thaw and 
https://doi.org/10.5194/tc-2021-60

Preprint. Discussion started: 7 April 2021

(c) Author(s) 2021. CC BY 4.0 License.

(c) (i)

Table 2. Maximum temperature difference between uphill and downhill observation sides $\left(\Delta \mathrm{T}_{\mathrm{E}}\right)$ at several depths within the active layer for each hillslope case; positive values indicate warmer temperatures occur uphill (steep or medium) compared to downhill.

\begin{tabular}{l|cccc|}
\hline$\Delta \mathbf{T}_{\mathbf{E}}$ & $0.1 \mathrm{~m}$ & $0.4 \mathrm{~m}$ & $0.8 \mathrm{~m}$ & $10 \mathrm{~m}$ \\
\hline steep & 1.18 & 1.01 & 0.80 & 0.87 \\
medium & 0.56 & 0.71 & 0.69 & 0.52 \\
\hline
\end{tabular}

Table 3. Maximum temperature difference between various hillslope inclination cases $\left(\Delta \mathrm{T}_{\mathrm{I}}\right)$ at several depths within the active layer; positive values indicate warmer temperatures occur in the sloped (steep or medium) cases compared to the flat case.

\begin{tabular}{l|cccc|cccc}
\hline \multirow{2}{*}{$\Delta \mathbf{T}_{\mathbf{I}}$} & \multicolumn{5}{|c|}{ uphill } & \multicolumn{4}{c}{ downhill } \\
& $0.1 \mathrm{~m}$ & $0.2 \mathrm{~m}$ & $0.4 \mathrm{~m}$ & $0.75 \mathrm{~m}$ & $0.1 \mathrm{~m}$ & $0.2 \mathrm{~m}$ & $0.4 \mathrm{~m}$ & $0.75 \mathrm{~m}$ \\
\hline steep-flat & 0.24 & 0.37 & 0.55 & 0.21 & -1.06 & -0.88 & -0.79 & -1.00 \\
medium-flat & 0.14 & 0.22 & 0.32 & -0.11 & -0.52 & -0.57 & -0.51 & -0.59 \\
\hline
\end{tabular}

before freeze-up. The warming occurs first close to the surface $(0.1 \mathrm{~m}$, orange line) exhibiting a temporal lag effect with depth. At $0.75 \mathrm{~m}$ depth (yellow) the warming effect is delayed and smaller due to the overall colder temperatures near the permafrost table. The greatest temperature differences can be seen near the surface $(0.1 \mathrm{~m}$ depth) at the onset of freeze-up in the steep case $\left(\sim 1.2^{\circ} \mathrm{C}\right.$ warmer than downhill)

Temperature differences $\Delta T_{I}$ between the steep slope and the flat case (Fig. 3c,d) and between the medium slope and the flat case (Fig. 3e,f) show that on the uphill side, the slopes are warmer in summer, colder during freeze-up and very similar to the flat case in winter. On the downhill side, the slopes are slightly colder than the flat case in winter and significantly colder during summer and just after freeze-up. During freeze-up however, the downhill sides are slightly warmer than the flat reference case.

An overview of the yearly maximum differences is given in Tables 2 and 3. The greatest temperature difference between uphill and downhill observation points occurs at $0.1 \mathrm{~m}$ depth $\left(\Delta \mathrm{T}_{\mathrm{E}}=1.18^{\circ} \mathrm{C}\right)$ for the simulation case with steep slope inclination (Table 2). Also, the steep slope case exhibits greater differences than the medium slope case for all depths in the active layer. Note however that the differences for the steep slope case are not quite double that of the medium slope case, despite the inclination being doubled.

Considering the temperature difference between slope inclination cases (Table 3), the greatest difference occurs when comparing the steep and flat cases, at $0.1 \mathrm{~m}$ depth on the downhill side $\left(\Delta \mathrm{T}_{\mathrm{I}}=-1.06^{\circ} \mathrm{C}\right)$. This indicates the importance of near-surface processes in summer on the downhill side. On the uphill side, the largest difference is visible at $0.4 \mathrm{~m}$ depth $\left(\Delta \mathrm{T}_{\mathrm{I}}=0.55^{\circ} \mathrm{C}\right)$. This inversion of temperature difference indicates that different processes are responsible for these differences in subsurface temperatures at various depths. 
https://doi.org/10.5194/tc-2021-60

Preprint. Discussion started: 7 April 2021

(c) Author(s) 2021. CC BY 4.0 License.

(c) (i)

Table 4. Average temperature of the entire transect up to $1.2 \mathrm{~m}$ depth for each day of the snapshots.

\begin{tabular}{l|cccccc|}
\hline & \multicolumn{6}{|c|}{ average temperature [ $\left.{ }^{\circ} \mathbf{C}\right]$} \\
& Jun 30 & Jul 20 & Aug 9 & Oct 28 & Nov 27 & Dec 7 \\
\hline steep & 0.73 & 1.76 & 2.02 & -0.76 & -0.95 & -5.72 \\
medium & 0.65 & 1.61 & 1.92 & -0.74 & -0.92 & -5.67 \\
flat & 0.64 & 1.56 & 1.82 & -0.73 & -0.87 & -5.64 \\
\hline
\end{tabular}

\subsection{Spatial analysis of ground temperatures}

210 The greatest difference in temperature along the subsurface transect is between the two outermost columns (at $x=0 \mathrm{~m}$ and $x=50 \mathrm{~m}$ ), corresponding to the two locations farthest apart along the hillslope. To better visualise the ground temperature differences between cases throughout the subsurface domain, the temperature difference between the steep and the flat case (Fig 4a), and the medium and flat case (Fig 4b) in the upper $1.2 \mathrm{~m}$ of the subsurface are considered. Note that Fig 4 shows cell-based temperature differences between cases; thus slope inclination is not depicted.

The upper three panels in each figure show snapshots of temperature differences during thaw (June) and summer (July, August), and the lower three panels show temperature differences during freeze-up (October, November) and winter (December). In both cases, the dates are separated by 20 days. For each day, the $0,{ }^{\circ} \mathrm{C}$ isotherm(s) from the steep and medium case respectively is (are) represented as black dotted line(s). The average temperature in this volume of the subsurface (upper $1.2 \mathrm{~m}$ ) is given in Table 4.

Ground temperatures in the sloped cases are generally warmer than in the flat case during thaw and summer (red shades). The temperature differences are greatest near the progressing thaw front, i.e. near the $0^{\circ} \mathrm{C}$ isotherm, as well as on the uphill side $(x=0 \mathrm{~m}$ ), but a gradual change towards same temperatures as the flat case (red to white) can be observed in the lateral direction (increasing $x$ ). Note also the last column on the downhill side $(x=50 \mathrm{~m})$ exhibits colder temperatures than the flat case (blue shades) during this time period. The temperatures below the permafrost table (at approximately $0.8 \mathrm{~m}$ depth) are only slightly warmer in the steep case, and essentially unchanged in the medium case, for the summer snapshots.

During freeze-up (October 28 and November 17 snapshots) the sloped cases are generally colder in the topsoil and warmer in the permafrost compared to the flat case. By winter (December 7) the entire $1.2 \mathrm{~m}$ depth of the steep slope becomes colder than the flat case (light blue), with the last column being significantly colder (dark blue). The medium slope case still has a small region in the uphill part of the domain close to the permafrost table that remains warmer than the flat case.

The $0{ }^{\circ} \mathrm{C}$ isotherms show that on June 30 , the steep slope already develops a deeper thawing front in the first $20 \mathrm{~m}$ of the transect compared to the medium slope. On July 20, the steep slope is warmer throughout most of the active layer thickness (approx. $0.8 \mathrm{~m}$ ) of the transect; only the last few meters of the domain $(x=45-50 \mathrm{~m})$ exhibit equal or cooler temperatures than the flat case. 


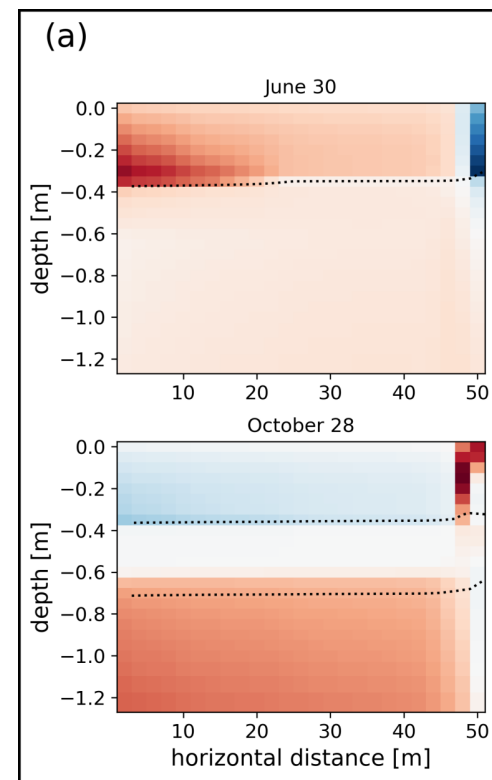

(b)
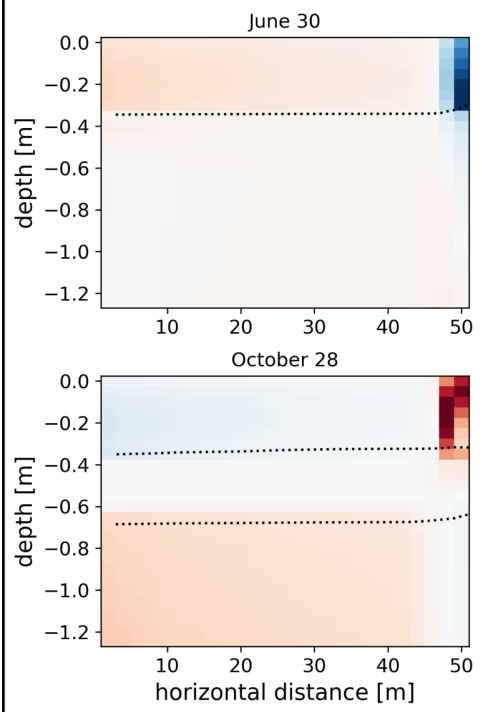
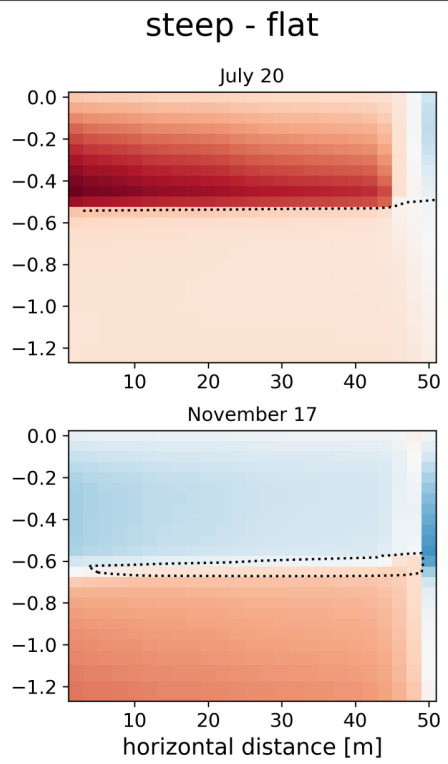

medium - flat
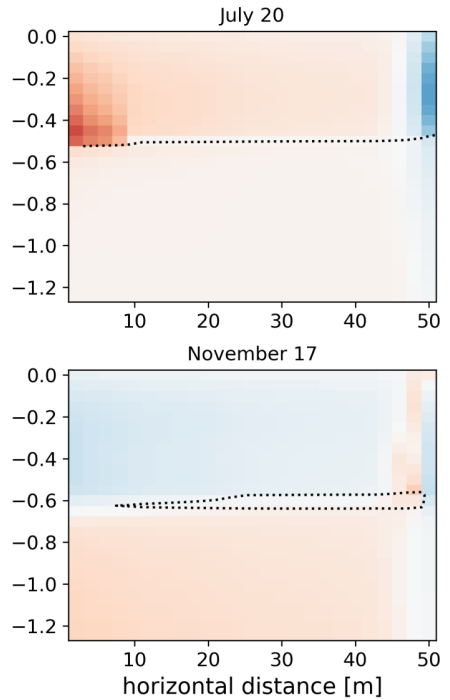
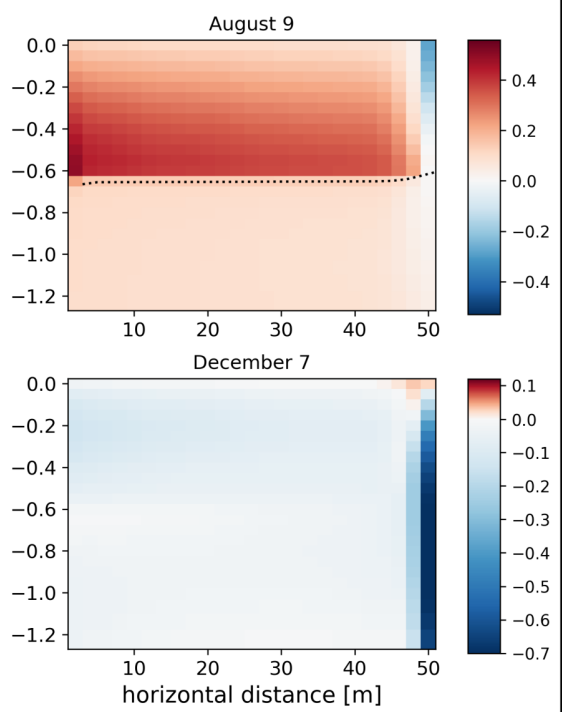

horizontal distance $[\mathrm{m}]$
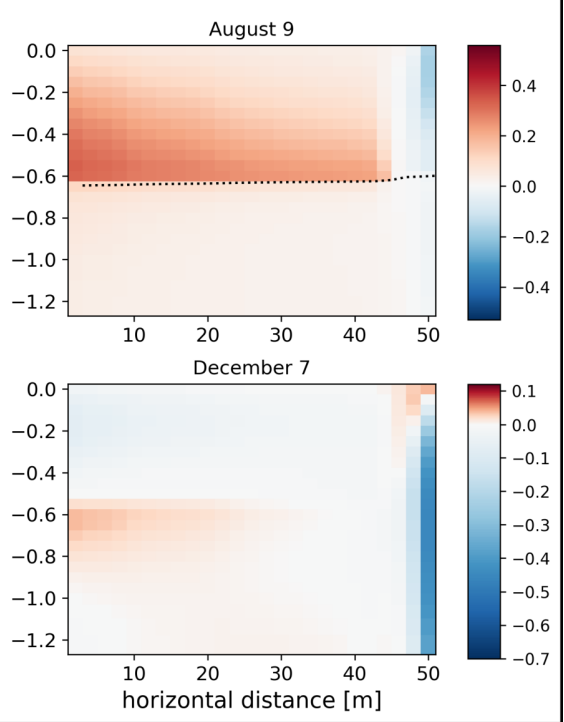

Figure 4. Temperature difference between (a) the steep and the flat case and (b) the medium and flat case at six selected dates highlighting thaw, summer, freeze-up and winter. Red colors indicate warmer temperatures in the hillslope cases than in the flat case, blue colors indicate cooler temperatures (note the color scale differs between summer and winter comparisons). The black dotted line indicates the $0{ }^{\circ} \mathrm{C}$ isotherm(s) in the corresponding hillslope case at the respective dates.

In the medium slope case, only the first $10 \mathrm{~m}(x=0-10 \mathrm{~m})$ of the slope show warmer temperatures in the active layer on that day, compared to the rest of the slope. In both cases, it can be seen that the last column $(x=50 \mathrm{~m})$ remains significantly cooler than the rest of the slope, causing the active layer to be shallower there. 

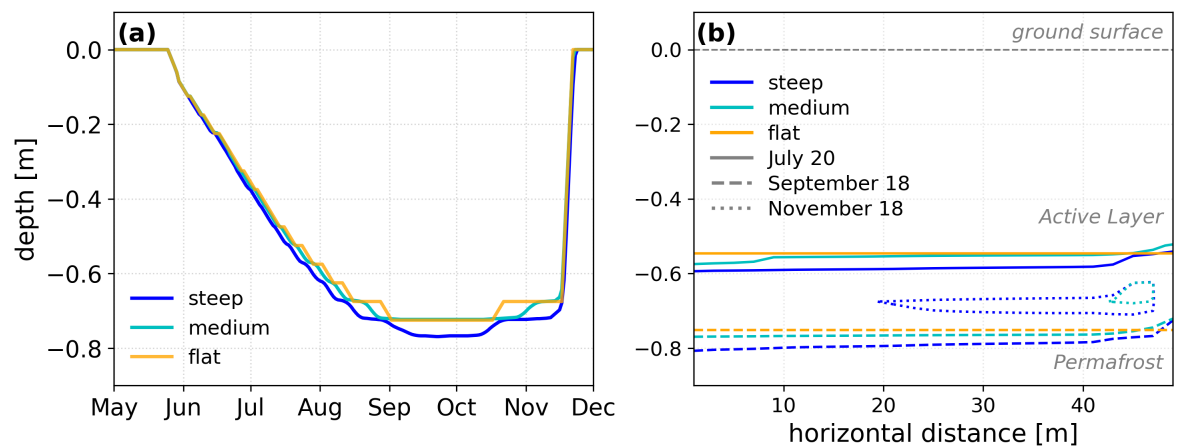

Figure 5. Representation of thaw depth compared between the steep (blue), medium (cyan) and flat case (yellow). (a) shows daily, spatially averaged thaw depth averaged over a 5-day window from May to December in the last year of the simulation. Note that thaw depth is defined as cells within the model domain that exceed $0{ }^{\circ} \mathrm{C}$. (b) shows snapshots of the developing thaw depth throughout the transect (defined as the $0{ }^{\circ} \mathrm{C}$ isotherm, vertically interpolated). Solid, dashed and dotted lines represent the three chosen points in time July 20 , September 18 , and November 18, respectively.

To highlight differences in the developing thaw depth between cases, spatially averaged thaw depths over the entire transect for each case are calculated (Fig. 5a). As noted above, the steep slope has a warming effect on the uphill section of the transect, which causes its maximum thaw depth (Fig. 5a, dark blue line) to be greater; spatial mean active layer depth on the date of maximum active layer depth is $-0.77 \mathrm{~m}$. On the other hand, the medium slope (cyan line) does not develop a substantially deeper maximum active layer thickness than the flat case, as the temperature difference is not enough to increase it ( -0.73 m maximum thaw depth in both cases). However, it can be seen that the medium slope case reaches maximum active layer thickness slightly earlier than the flat case (yellow) and freezes up slower, reflecting the slightly warmer temperatures.

Three snapshots of the thaw progression throughout the subsurface during the summer and freeze-up seasons are shown in Fig. 5b. The steep slope case (dark blue) has the deepest thaw depth in July throughout most of the transect (max. $-0.6 \mathrm{~m}$ ), between $x=0-45 \mathrm{~m}$, while the medium case (cyan) has a similar thaw depth (max. $-0.58 \mathrm{~m}$ ) as the flat case (yellow, max. $-0.55 \mathrm{~m}$ ) for lateral distances between $x=10-48 \mathrm{~m}$ ( $5 \mathrm{~b}$, solid lines). Between $x=0$ to $10 \mathrm{~m}$ the thaw depth in the medium case in July is deeper and the last two meters ( $x=48$ to $50 \mathrm{~m}$ ) shows a shallower thaw depth as compared to the flat case. This observation on thaw depths for July 20 is consistent with the previously discussed temperature differences in Figure 4; temperatures are generally warmer uphill and cooler downhill for the sloped cases, and the cooling effect is primarily observed within the last few meters of the domain.

On the date of maximum thaw depth, corresponding to the active layer thickness (September 18, dashed lines), the steep case shows the deepest active layer ( $\max .-0.81 \mathrm{~m}$ ), while the medium case is only slightly deeper than the flat case (max. $-0.77 \mathrm{~m}$ and $0.75 \mathrm{~m}$, respectively). Both slopes show a shallower active layer in the last few meters of the transect ( $x=45$ to $50 \mathrm{~m}$ ). This again is consistent with the previously discussed temperature differences, where generally significantly cooler temperatures are observed on the downhill side than on the uphill side $\left(\Delta \mathrm{T}_{\mathrm{E}}\right)$ and the slopes being colder than the flat case $\left(\Delta \mathrm{T}_{\mathrm{I}}\right.$ 
https://doi.org/10.5194/tc-2021-60

Preprint. Discussion started: 7 April 2021

(c) Author(s) 2021. CC BY 4.0 License.

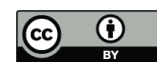

During freeze-up on November 17 (dotted lines), the flat case has attained a fully frozen active layer. The sloped cases however still exhibit unfrozen patches of soil ("thaw bulbs") between 0.6 and $0.8 \mathrm{~m}$ depth. This indicates that the temperature changes caused by slope inclination, specifically warmer temperatures in the uphill-center sections of the transect, creates a delay in freeze-up especially towards the center-downhill sections of the domain. However, the previously warmest parts of the sloped cases during summer are already frozen at this time, which is related to latent heat consumption differences in the different parts of the transect.

A further observation is that two-sided freezing occurs. This is evident by the remaining thaw bulb with encroaching freezing front both from above as well as below (dotted lines). Subsequently, the active layer is fully frozen again on November 20 for the steep slope case, on November 19 for the medium slope case, and finally on November 18 for the flat case.

In summary, we observe that the steep slope case has a notable influence on thaw propagation and active layer thickness, which we attribute to an increase in ground temperatures compared to the flat case, observed primarily in the center-uphill side of the subsurface during most of the summer period. The warming effect in the medium slope case is not sufficiently strong to increase the active layer in most of the transect compared to the flat case. This results in a active layer thickness of $0.81 \mathrm{~m}, 0.77 \mathrm{~m}$ and $0.75 \mathrm{~m}$ for the steep, medium and flat case respectively. However, the warming effect for the medium slope causes maximum thaw depth to be reached earlier and freeze-up to be delayed. This can be seen by integrating the total volume of unfrozen soil over the warm season (defined as days with at least one unfrozen cell in the subsurface model domain, here resulting in May 16 to November 20; 187 days). The steep slope amounts to a total volume of $2297 \mathrm{~m}^{3}$ (or an average of $12.3 \mathrm{~m}^{3}$ per day), the medium slope amounts to $2202 \mathrm{~m}^{3}$ (average $11.8 \mathrm{~m}^{3}$ per day), and the flat slope amounts to $2175 \mathrm{~m}^{3}$ (average of $11.6 \mathrm{~m}^{3}$ per day). This indicates that the slopes in general have a greater unfrozen volume of soil, even though the active layer is not necessarily deeper in the medium slope. Hence, the warming effect due to slope inclination does not only play a role in the vertical soil profile, but also in the timing of freeze and thaw.

\subsection{Saturation and thermal conductivity}

Due to lateral gravitational water flow during the warm period, moisture accumulates on the downhill side, and yields greater liquid saturation there when compared against the flat reference case which is not subject to lateral flow (Fig. 6, first column). This leads subsequently to greater ice saturation on the downhill side during the frozen period (Fig. 6 second column). The increased ice and liquid saturation in the slopes, and consequently reduced air saturation (Fig. 6 third column), results in a considerably greater effective thermal conductivity during winter and slightly greater effective thermal conductivity during summer (Fig. 6 fourth column). Considering the little snow cover in winter (max. $0.01 \mathrm{~m}$, see Fig. S2), the effect should be an enhanced heat loss (cooling of the ground) during winter, and slightly enhanced heat gain (warming of ground) during summer, when compared against the flat reference case.

Recall the previous discussion on temperature differences between the sloped and flat cases (Fig. 3d,f). The downhill side of the sloped cases experience cooler winter temperatures, especially shortly after freeze-up in late November. This is consistent with the differences in effective thermal conductivity, as an increased thermal conductivity during cold periods enables an enhanced ground heat loss, yielding cooler winter ground temperatures. However, summer temperatures also exhibit significant 

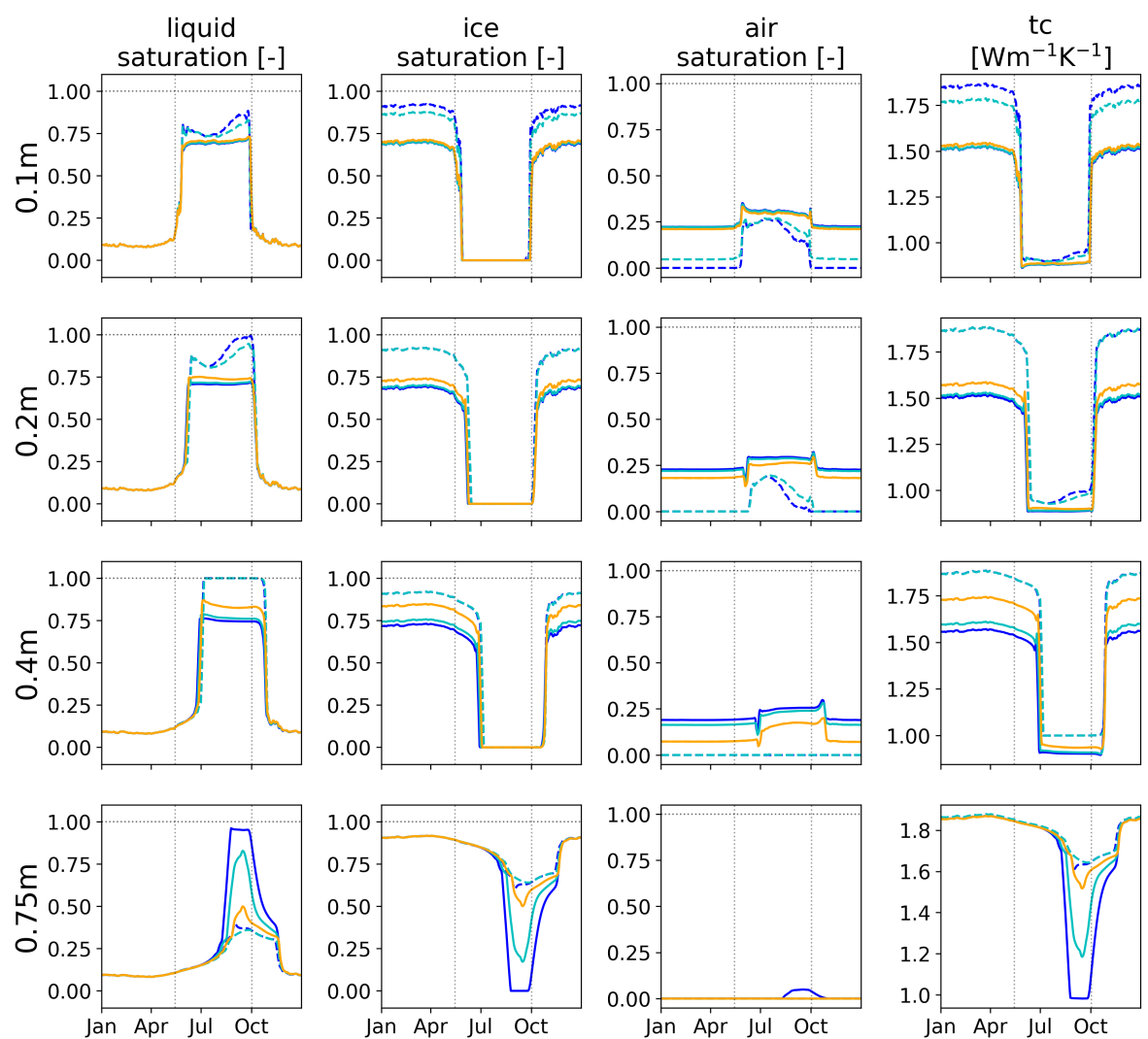

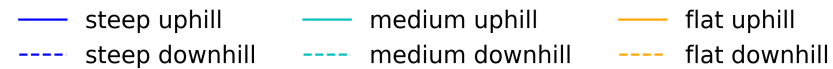

Figure 6. Daily values for liquid, ice, and air saturation (columns 1-3) and thermal conductivity (column 4) at 0.1,0.2, 0.4 and 0.75 m depth (rows 1-4). Colors represent the three different cases and solid and dashed lines mark uphill and downhill sides, respectively. The horizontal dashed lines in the saturation plots indicate $100 \%$ saturation. The vertical dashed lines mark the first and last day at which ground surface temperatures exceed $0^{\circ} \mathrm{C}$

cooling when compared to the flat case (Fig. 3d,f). This is not consistent with the increased effective thermal conductivity summertime, as it should enhance heat uptake to the ground, leading to warmer ground temperatures. Thus we conclude changes in effective thermal conductivity alone does not suffice to explain the temperature changes incurred on the downhill side of the domain for the two hillslope cases.

Next, consider the uphill side of the domain for the hillslope cases. They are slightly drier at depths $0.2 \mathrm{~m}, 0.4 \mathrm{~m}$ and $0.75 \mathrm{~m}$, both for summer with less liquid saturation, and winter with less ice saturation (Fig. 6, first and second columns, respectively). This slightly reduces effective thermal conductivity with respect to the flat case at those depths, mainly in winter and slightly discernible also in summer (Fig. 6, fourth column). Thus, when compared against the flat reference case, the uphill side of the inclined cases should exhibit warmer ground temperatures during winter due to reduced thermal conductivity (greater 
https://doi.org/10.5194/tc-2021-60

Preprint. Discussion started: 7 April 2021

(c) Author(s) 2021. CC BY 4.0 License.

(c) (i)

insulation) and hence reduced heat loss. During summer, the reduced thermal conductivity is only minor, but if anything may lead to a reduced heat gain, leading to slightly cooler ground when compared to the flat case. However, this is not entirely consistent with the previously observed temperature differences for the uphill side (see Figures $3 \mathrm{c}, \mathrm{e}$ ); while winter temperature differences are small between the sloped and flat cases, summer temperatures are warmer in the sloped cases, not cooler. The greatest difference for both slopes can be found at $0.4 \mathrm{~m}$ depth, with smaller difference closer to the surface. During freeze-up, the uphill sides are cooler than the flat case. This is also apparent for the downhill side.

When only comparing the two observation locations uphill vs. downhill within the slopes (Fig. 3a,b), similar effects as previously described can be seen. Again, winter differences can be explained by increased heat loss to the atmosphere due to greater thermal conductivity on the downhill side, but summer differences cannot be explained by changes in saturation and effective thermal conductivity alone.

In summary, moisture redistribution causes thermal conductivity to be greater downhill than uphill, causing changes to the effective thermal conductivity along the lateral transect for hillslopes. Although this impacts the diffusive transport of energy (heat conduction) through the subsurface, summer ground temperatures cannot be linked directly to differences in effective thermal conductivity; this is further investigated by studying heat fluxes in the next section.

\subsection{Energy fluxes}

315 Vertical and lateral energy fluxes are calculated through the faces of two control volumes in the subsurface domains; one placed on the uphill side and the other on the downhill side (see Fig. 2). The objective is to investigate fluxes within the active layer, hence the $\mathrm{CVs}$ extend from $0.1 \mathrm{~m}$ depth to $0.6 \mathrm{~m}$ depth below the surface. Daily flux values are considered, defined as positive if entering the $\mathrm{CV}$, and negative if leaving the CV. Diffusive heat flux (energy transport by conduction) and advective heat flux (energy transport by water flow) obtained this way are shown in Figs. 7 and 8, respectively, for both the uphill CV (solid lines) and downhill CV (dashed lines). The central box (conceptually) aids the interpretation of the fluxes across corresponding faces of the control volume. Fluxes across the top and bottom faces represent fluxes at $z=-0.1$ and $z=-0.6 \mathrm{~m}$ depth, while fluxes across the left and right faces represent fluxes across vertical faces at $x=48$ and $x=2 \mathrm{~m}$, respectively. The distance is given as distance from the left domain boundary $(x=0 \mathrm{~m})$. Note the lateral fluxes are only displayed on one of the vertical faces of the CVs due to their location on the domain-boundaries, as the opposing sides ( $x=50$ and $x=0 \mathrm{~m}$ ) are no-flow boundaries. Fluxes can vary by more than one order of magnitude between cases, which results in different ranges of values for the vertical axes.

The most pronounced flux is vertical diffusion $\left(-20-20 \mathrm{~W} \mathrm{~m}^{-2}\right)$, which shows little relative difference between the hillslope cases. Across the top face, i.e. at $0.1 \mathrm{~m}$ depth, the downhill CVs (Fig. 7a, dashed) show slightly greater heat gain through diffusion in summer (up to $5 \mathrm{~W} \mathrm{~m}^{-2}$ ) and slightly greater heat loss during freeze-up, than the uphill CVs (solid). Winter diffusive heat fluxes are almost identical. Lateral heat diffusion is smaller, but more pronounced and quite variable in the downhill CVs (Fig. 7b, dashed, $-0.1-0.7 \mathrm{~W} \mathrm{~m}^{-2}$ ). It is highest during freeze-up and in winter, which is due to a high temperature gradient between the penultimate and the last column in the model domain. 


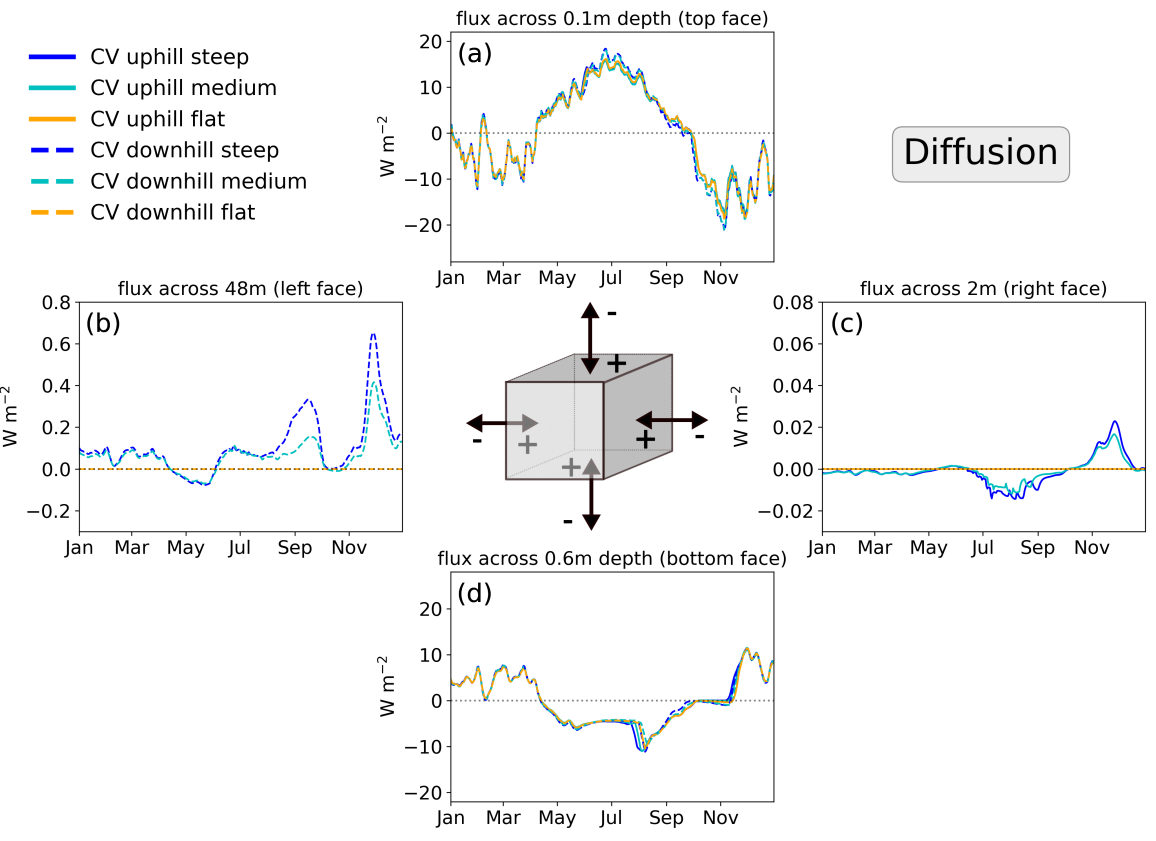

Figure 7. Daily values of diffusive heat flux on the faces of the control volume (CV; 7-day moving average) at the uphill (solid) and downhill (dashed) CV locations. Colors represent the steep (blue), medium (yellow) and flat (green) case, respectively. The sign convention adopted is positive values represent heat entering the $\mathrm{CV}$ and negative values leaving the CV. Due to the definition of the CV boundaries, lateral fluxes only occur on the right face for CV up and on the left side for CV down.

In the uphill CV (Fig. 7c, solid), the lateral heat diffusion is more than one order of magnitude smaller $\left(-0.02-0.03 \mathrm{~W} \mathrm{~m}^{-2}\right)$ and heat is being lost in summer, but gained during freeze-up. This is also consistent with the warming and the reduced effective thermal conductivity observed on the uphill side of the domain, which combined should yield a decreased heat flux.

Advective heat flux magnitudes are generally much smaller than diffusive flux magnitudes (Fig. 8). Note that advective fluxes only occur in summer and during freeze-up, i.e. when unfrozen water is available for flow, and further only occur for the sloped cases (steep and medium); the flat case exhibits zero values for advective (lateral) flux, as expected. Note also that the magnitude of lateral advective heat flux is about one order of magnitude larger on the downhill side (Fig. 8b, dashed) than on the uphill side (Fig. 8c, solid).

As water flows and accumulates downhill, the heat carried by water causes the lateral heat flux magnitude to increases downhill. This can be seen by the flux magnitude across the $x=2 \mathrm{~m}$ face (Fig. 8c, uphill) being much smaller than across the $x=48 \mathrm{~m}$ face (Fig. $8 \mathrm{~b}$, downhill). Thus, the increase in lateral advective heat flux should contribute to warmer ground temperatures on the downslope side of the domain. However, summer temperature differences between the up- and downhill column show that the downhill columns $(x=48-50 \mathrm{~m})$ are in fact cooler, rather than warmer (see Fig. 3a,b). Therefore, we conclude that the lateral advective heat flux, although present, is not sufficient to increase ground temperatures on the downhill side of the domain. Therefore, another mechanism must be active which inhibits this small warming, and also causes the 
https://doi.org/10.5194/tc-2021-60

Preprint. Discussion started: 7 April 2021

(c) Author(s) 2021. CC BY 4.0 License.

(c) (i)

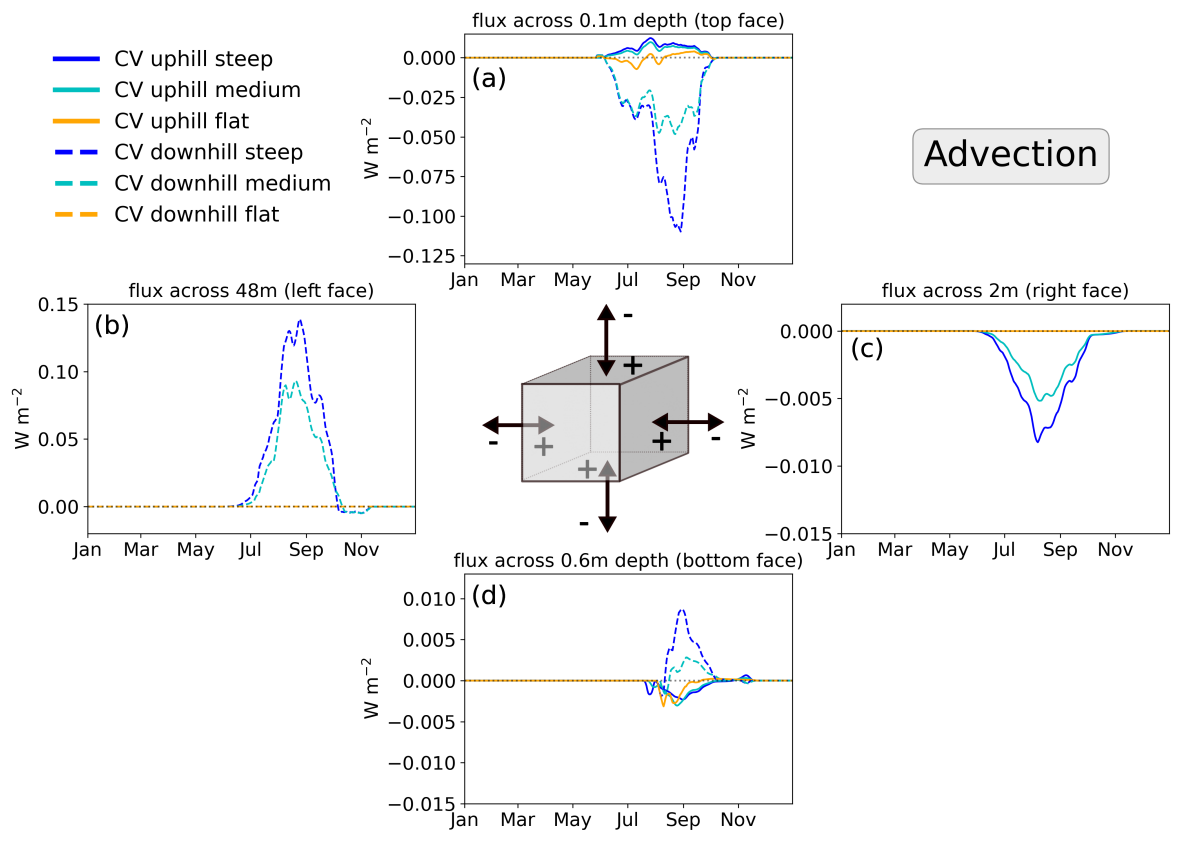

Figure 8. Daily values of advective heat flux on the faces of the control volume (CV; 7-day moving average) at the uphill (solid) and downhill (dashed) CV locations. Colors represent the steep (blue), medium (yellow) and flat (green) case, respectively. The sign convention adopted is positive values represent heat entering the $\mathrm{CV}$ and negative values leaving the $\mathrm{CV}$. Due to the definition of the CV boundaries, lateral fluxes only occur on the right face for CV up and on the left side for CV down.

downhill side to cool. This implies that the lateral flow of water, which carries heat, has a negligible effect on the warming towards downhill, based on the model configuration and weather forcing assumed.

Next consider vertical advection across the near-surface face at $0.1 \mathrm{~m}$ depth (Fig. 8a), which is strongly influenced by the uphill vs. downhill side along the hillslope. While the flat case shows values varying around $+/-0.005 \mathrm{~W} \mathrm{~m}^{-2}$ in summer, i.e. corresponding to negligible heat flux, the sloped cases have consistently positive values on the uphill side (solid) and consistently negative on the downhill side (dashed) during the same period. This gain and loss of heat on the top CV face $(z=0.1 \mathrm{~m})$ can be explained by surface precipitation (positive, i.e. heat gain) and evaporation (negative, i.e. heat loss). The positive heat flux on the uphill side is dominated by infiltration. As this is the driest part of the transect, it provides less moisture available for evaporative cooling. This energy flux directed towards the subsurface explains why the uphill part of the transect is warmer during summer (Fig. 4, upper panels). The negative flux on the downhill side is a result of evaporation, which transports water and heat upwards out of the model (i.e. corresponding to heat lost to the atmosphere). Evaporative flux directly at the surface $(z=0 \mathrm{~m})$ is given in Fig. $\mathrm{S} 3$ in the supplementary material. 

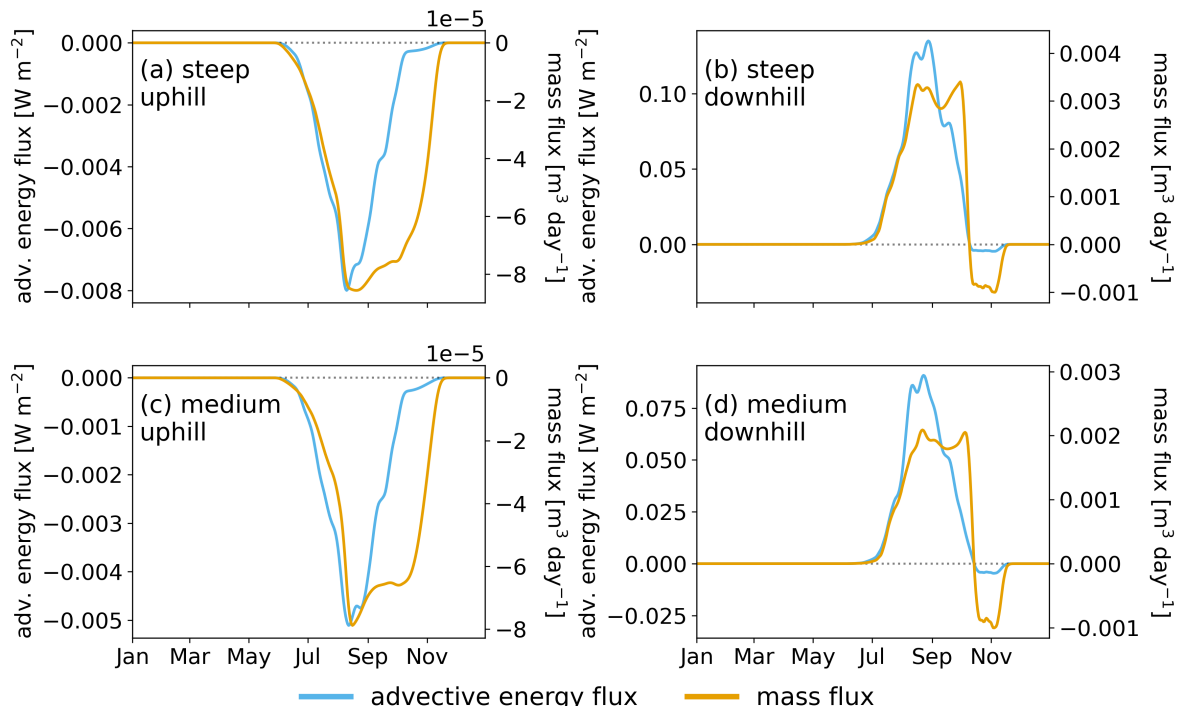

Figure 9. Daily advective energy flux and mass flux (7-day moving average) through the faces of the uphill (a,c) and downhill (b,d) CV. Note that the fluxes have different units. The sign convention adopted is positive values represent heat entering the $\mathrm{CV}$ and negative values leaving the $\mathrm{CV}$.

\subsection{Combined mass and energy fluxes}

To further understand how much energy is carried by seeping water, we compare the lateral advected energy flux on the left or right faces of the CVs alongside the water mass flux on the same faces, and compare the timing of peaks (Fig. 9; a complete presentation of the mass fluxes across all faces is provided in Fig. S4 in the supplementary material). Note that units between advective heat flux and mass flux are different and that the following interpretation focuses on the shape of the curves, rather than absolute values. As can be seen (Fig. 9), advective heat flux (blue) peaks before September in both uphill and downhill CVs and declines shortly after. Mass flux (yellow) also has its first peak before September, but with prolonged duration of flow and declines gradually.

For the uphill $\mathrm{CV}$, it can be seen that advective heat flux is close to zero already by the end of September, while mass flux reaches zero only by mid November. The downhill CVs exhibit a second, less distinct mass flux peak just before and during freeze-up in the end of October, which is however not associated with a peak in advective heat flux. This indicates that heat is being carried with water flow during the warm season, corresponding to mid-thaw period, but little advective heat is being transported by the end of the thaw season. This is caused by the permafrost acting as a significant heat sink and reservoir for cooling of the soil column above. Infiltrating water from the surface gets cooled down rapidly causing it to attain equilibrium with its surroundings. Then, although water seepage and flow occurs, it does not contribute much to advective heat transport, as the flowing water is at the same temperature as its surroundings. 
https://doi.org/10.5194/tc-2021-60

Preprint. Discussion started: 7 April 2021

(c) Author(s) 2021. CC BY 4.0 License.

(c) (i)

During freeze-up (November), moisture movement uphill can be seen (Fig. 9b,d, negative values), which is indicative of lateral cryosuction.

\subsection{Impact of changes in precipitation}

In order to investigate the effects of reduced or increased precipitation, two additional wetness scenarios are considered for each hillsope; a dry scenario (S0R0) and scenario with increased wetness (S2R2). Snow (S) and rain (R) precipitation rates are set to 0 for S0R0, resulting in a completely dry climate, and the rates are multiplied by 2 in the S2R2 scenario, resulting in a climate that is twice as wet as the current climate. We compare the scenarios with regard to temperature differences, active layer thickness, timing of freeze-up, and advective energy flux.

Firstly, we find that both slopes and the flat case are notably warmer in the no-precipitation scenario and colder in the doubled precipitation scenario. Relative temperature differences between the slopes are generally in a similar range as in the original precipitation scenario with the exception of the downhill side (last column of the domain) in the S2R2 scenario being even colder. On October 28 , the downhill side is as much as $-1.3^{\circ} \mathrm{C}$ colder in the steep case compared to the flat case, while the original precipitation scenario showed a maximum difference of $-0.25^{\circ} \mathrm{C}$ on the same day. In the dry S0R0 scenario the difference is only $-0.09^{\circ} \mathrm{C}$ on the same day between the steep and the flat case. A similar pattern can be seen consistently throughout the year.

Active layer thickness further support these findings. Maximum active layer thickness is deepest in the scenario with no precipitation (steep: $0.975 \mathrm{~m}$, medium and flat: $0.925 \mathrm{~m}$ ), while it is the shallowest in the doubled precipitation scenario (steep: 0.625 m, medium and flat: $0.575 \mathrm{~m}$ ) (supplementary material Fig. S5 and Fig. S6). Note that the difference in absolute maximum active layer thickness between the medium and flat slope is very small averaged throughout the transect. Due to the temperature difference, however, the medium case experiences an earlier thaw and delayed freeze-up in the sensitivity scenarios as well as in the original scenario.

The timing of freeze-up is different throughout the inclinations in each scenario. In the original scenario, all cases are fully frozen again on November 20. While the scenario with no precipitation (SOR0) also shows the latest freeze-up on November 20, in S2R2 the last day with unfrozen subsurface-cells is November 3, about two weeks earlier than in the other two scenarios. Overall, the scenarios show that the higher the amount of recharge added through precipitation on the surface, the lower the ground temperatures will be in the both the sloped cases as well as the flat case. Note that multiplying snow by a factor of 2 still did not result in a snow cover significant enough to have an insulating effect on the subsurface.

These results are consistent with previously observed cooling effect of precipitation on the active layer. Wen et al. (2014) and Wu and Zhang (2008) both documented a cooling of the active layer in response to rainfall on the Tibetan Plateau. In contrast, e.g., Douglas et al. (2020) and Mekonnen et al. (2021) found a warming effect of summer precipitation on active layer temperatures. However, those studies do not account for the influences of topography.

As for heat fluxes along the faces of the CVs, we find that most fluxes follow the overall observed patterns in the original simulation depending on moisture content. For instance, diffusive heat flux in summer near the surface is lowest in the dry case S0R0 due to lower saturation, highest in the wetter case S2R2, and with the original precipitation scenario located in between. 
https://doi.org/10.5194/tc-2021-60

Preprint. Discussion started: 7 April 2021

(c) Author(s) 2021. CC BY 4.0 License.

(c) (i)

Vertical advection, i.e. heat carried by infiltration and/or evaporation processes, show that additional moisture in the downhill column further increase evaporation. However, while upwards advective heat flux in the steep case in the original scenario has a maximum of $\sim-0.1 \mathrm{~W} \mathrm{~m}^{-2}$, it increases by a factor of three to $\sim-0.3 \mathrm{~W} \mathrm{~m}^{-2}$ in the S2R2 case. This likely leads to an even greater evaporative cooling effect in the downhill column. A similar non-linear development can be seen in lateral advective heat flux. Although still very small in absolute values, lateral advection also increases by a factor of three between the original and the S2R2 case from $\sim 0.04$ to $\sim 0.12 \mathrm{~W} \mathrm{~m}^{-2}$.

These findings imply that potential future changes in air temperatures and precipitation towards a warmer and wetter climate could have opposing effects on subsurface temperatures. While higher summer temperatures have a high potential to increase active layer thickness in a catchment, higher precipitation amounts could counteract these processes and act as a heat sink.

Therefore, the interaction of warmer temperatures and increased precipitation rates under change climates warrants investigation. Moreover, a transient development of temperature and precipitation is likely to yield a different result than our step-wise increase of precipitation alone. Potentially, a deeper active layer might lead to a greater volume of unfrozen soil and water, which is available for transport (Walvoord and Kurylyk, 2016). This could then lead to even higher non-linearly increasing advective heat fluxes that could eventually contribute to the energy budget downhill.

\subsection{Further implications}

Our study has shown that there are differences in the thermal-hydraulic state of the subsurface between the uphill and the downhill side of a $50 \mathrm{~m}$ long hillslope transect. Vertical advective heat fluxes (infiltration and evaporative cooling) play a major role in this comparison causing a great share of the differences between the flat control case and the slopes. Evaporative cooling has previously been identified as one of the major non-conductive heat fluxes causing a subsurface cooling in permafrost landscapes (Kane et al., 2001; Wu and Zhang, 2008; Wen et al., 2014; Li et al., 2019; Luo et al., 2020). Lateral advective heat flux in this continuous, high Arctic permafrost landscape with generally low hydraulic conductivity and low precipitation amounts is not sufficient to increase temperatures downhill, corresponding to e.g., a valley bottom. In fact, we observe a contrary effect, such that lateral flow increases moisture content downhill, contributing to enhanced evaporation and evaporative cooling downhill.

Other advancements in 2D permafrost modeling have shown that lateral advection of heat in sub-Arctic, discontinuous permafrost landscapes can significantly change the temperature regime of the subsurface as well as the timing of thaw and freeze-up (Sjöberg et al., 2016). Shojae Ghias et al. (2019) also showed in several model setups that a combined conductionadvection scenario causes an increased permafrost thaw as opposed to a conduction-only scenario. This highlights how different advective heat transport affects different landscapes. Under conditions with lower hydraulic conductivity within the subsurface and no topography, advective heat flux has found to not have such a significant impact on the temperature regime (Kurylyk et al., 2016), which is in line with our findings. This implies that processes found in our study are more relevant for a high-Arctic hillslope setting.

The observed downhill cooling effect of up to about $1.2^{\circ} \mathrm{C}$ for steep $\left(22^{\circ}\right)$ and $0.6^{\circ} \mathrm{C}$ for medium $\left(11^{\circ}\right)$ inclinations is obtained for a model domain with lateral distance of $50 \mathrm{~m}$. We generalize these results by calculating lateral and vertical cooling 
https://doi.org/10.5194/tc-2021-60

Preprint. Discussion started: 7 April 2021

(c) Author(s) 2021. CC BY 4.0 License.

(c) (i)

rates based on the slope inclinations.For the steep slope case, this results in a lateral cooling rate of $0.026^{\circ} \mathrm{C} / \mathrm{m}$ and a vertical cooling rate of $0.065^{\circ} \mathrm{C} / \mathrm{m}$. For the medium slope, the lateral cooling rate amounts to $0.015^{\circ} \mathrm{C} / \mathrm{m}$. The vertical cooling rate is slightly higher $\left(0.075^{\circ} \mathrm{C} / \mathrm{m}\right)$ than in the steep slope case. These rates are representative for slopes in the Adventdalen area in Svalbard under current climatic conditions.

Projecting these results to larger scales, hillslope processes might cause significant differences in permafrost distributions throughout a catchment. As our slopes were limited to $50 \mathrm{~m}$ in horizontal distance, it can be expected that longer slopes aggregate more water towards the downhill side, eventually leading to fully saturated conditions. At the same time, lateral advective heat fluxes have shown to increase non-linearly with increasing precipitation, which might also be observable in larger scale hillslope systems due to higher water availability. Considering a full, 3D representation of a hillslope, it is likely that the micro topography within the slope causes further concentration of moisture, eventually leading to water tracks, which have shown to act as conduits for groundwater even if the adjacent hillslope is already frozen (Evans et al., 2020). These features might substantially change the observed effects in this homogeneous $2 \mathrm{D}$ representation of a hillslope without micro topography.

\section{Conclusions}

Based on the objectives and investigation questions outlined in this study, the main conclusions are as follows.

(i) Hillslope inclination causes differences in ground temperature uphill and downhill. We found that downhill sides are generally cooler than uphill sides. This downhill cooling effect is up to about $1.2^{\circ} \mathrm{C}$ for steep $\left(22^{\circ}\right)$ and $0.6^{\circ} \mathrm{C}$ for medium $\left(11^{\circ}\right)$ inclinations across a lateral distance of $50 \mathrm{~m}$ representative for valleys in Adventdalen, Svalbard.

(ii) The steep slope causes ground warming on the uphill section powerful enough to increase maximum active layer depth by $5 \mathrm{~cm}(0.8 \mathrm{~m})$ as compared to the flat case $(0.75 \mathrm{~cm})$. The medium slope, on the other hand, does not incur sufficient warming uphill to significantly increase thaw depth compared to the flat case. However, the total volume of unfrozen soil during the warm season increased by $5.7 \%$ in the steep slope case, and $1.2 \%$ in the medium slope case.

(iii) The downhill cooling phenomena observed here is determined to be caused by two main processes:

1. Higher moisture content downhill, due to gravitational flow and water accumulation from uphill, which increases effective thermal conductivity and associated heat loss to the atmosphere in winter.

2. In summer, higher moisture content causes higher rates of evaporation resulting in greater evaporative cooling compared to the uphill side, where infiltrating precipitation actually outweighs evaporation and actually adds energy to the system.

We found that temperature difference effect from a flat case, over a medium steep slope $\left(11^{\circ}\right)$ to a steep slope $\left(22^{\circ}\right)$ is not strictly linear and does not double between the two sloped cases. Lateral heat advection, i.e. energy carried by flowing water, only plays a minor role for the temperature differences between uphill and downhill. 
https://doi.org/10.5194/tc-2021-60

Preprint. Discussion started: 7 April 2021

(c) Author(s) 2021. CC BY 4.0 License.

(c) (i)

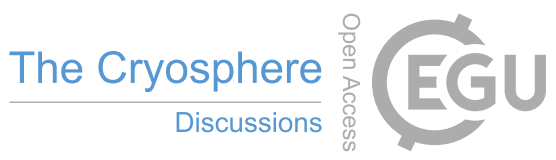

This finding, although based on numerical physically-based modelling, should be observable in field conditions. It highlights the relevance of considering lateral flow of water in the subsurface combined with heat flux for modelling arctic catchments with permafrost. It also has implications for interpretation of thermal measurements and time series logging.

Code and data availability. The Advanced Terrestrial Simulator(ATS) (Coon et al., 2019) is open source under the BSD 3-clause license and is publicly available at https://github.com/amanzi/ats (last access: July 2020). Simulations were conducted using version 0.88. Forcing datasets and input files are available at https://github.com/a-hamm/ats_hillslope2021.git. Weather data to create the forcing dataset was downloaded from the UNIS website (https://www.unis.no/resources/weather-stations/) (last access March 2020) and from the Norwegian Meteorological Institute (https://www.eklima.met.no) (last access March 2020).

Author contributions. Both authors conceived the initial conceptualization. Model simulations were performed by AH with guidance from AF. AH wrote the manuscript with contribution from AF.

Competing interests. The authors declare that they have no conflict of interest.

Acknowledgements. This work is funded by Formas (project 2017-00736) with support from the Bolin Centre for Climate Research. The authors also thank Ahmad Jan and Ethan Coon for technical support with ATS. 
https://doi.org/10.5194/tc-2021-60

Preprint. Discussion started: 7 April 2021

(c) Author(s) 2021. CC BY 4.0 License.

(c) (i)

\section{References}

Atchley, A. L., Painter, S. L., Harp, D. R., Coon, E. T., Wilson, C. J., Liljedahl, A. K., and Romanovsky, V. E.: Using field observations to inform thermal hydrology models of permafrost dynamics with ATS (v0.83), Geoscientific Model Development, 8, 2701-2722, https://doi.org/10.5194/gmd-8-2701-2015, https://www.geosci-model-dev.net/8/2701/2015/, 2015.

Biskaborn, B. K., Smith, S. L., Noetzli, J., Matthes, H., Vieira, G., Streletskiy, D. A., Schoeneich, P., Romanovsky, V. E., Lewkowicz, A. G., Abramov, A., Allard, M., Boike, J., Cable, W. L., Christiansen, H. H., Delaloye, R., Diekmann, B., Drozdov, D., Etzelmüller, B., Grosse, G., Guglielmin, M., Ingeman-Nielsen, T., Isaksen, K., Ishikawa, M., Johansson, M., Johannsson, H., Joo, A., Kaverin, D., Kholodov, A., Konstantinov, P., Kröger, T., Lambiel, C., Lanckman, J.-P., Luo, D., Malkova, G., Meiklejohn, I., Moskalenko, N., Oliva, M., Phillips, M., Ramos, M., Sannel, A. B. K., Sergeev, D., Seybold, C., Skryabin, P., Vasiliev, A., Wu, Q., Yoshikawa, K., Zheleznyak, M., and Lantuit, H.: Permafrost is warming at a global scale, Nature Communications, 10, 264, https://doi.org/10.1038/s41467-018-08240-4, http://www.nature.com/articles/s41467-018-08240-4, 2019.

Chen, L., Fortier, D., McKenzie, J. M., and Sliger, M.: Impact of heat advection on the thermal regime of roads built on permafrost, Hydrological Processes, 34, 1647-1664, https://doi.org/10.1002/hyp.13688, https://onlinelibrary.wiley.com/doi/abs/10.1002/hyp.13688, 2020.

Coon, E., Svyatsky, D., Jan, A., Kikinzon, E., Berndt, M., Atchley, A., Harp, D., Manzini, G., Shelef, E., Lipnikov, K., Garimella, R., Xu, C., Moulton, D., Karra, S., Painter, S., Jafarov, E., and Molins, S.: Advanced Terrestrial Simulator, https://doi.org/10.11578/DC.20190911.1, https://www.osti.gov/doecode/biblio/28622, language: en, 2019.

Coon, E. T., David Moulton, J., and Painter, S. L.: Managing complexity in simulations of land surface and near-surface processes, Environmental Modelling \& Software, 78, 134-149, https://doi.org/10.1016/j.envsoft.2015.12.017, https://linkinghub.elsevier.com/retrieve/ pii/S1364815215301316, 2016.

de Grandpré, I., Fortier, D., and Stephani, E.: Degradation of permafrost beneath a road embankment enhanced by heat advected in groundwater, Canadian Journal of Earth Sciences, 49, 953-962, https://doi.org/10.1139/e2012-018, http://www.nrcresearchpress.com/doi/10.1139/ e2012-018, 2012.

Douglas, T. A., Turetsky, M. R., and Koven, C. D.: Increased rainfall stimulates permafrost thaw across a variety of Interior Alaskan boreal ecosystems, npj Climate and Atmospheric Science, 3, 28, https://doi.org/10.1038/s41612-020-0130-4, http://www.nature.com/articles/ s41612-020-0130-4, 2020.

Evans, S. G. and Ge, S.: Contrasting hydrogeologic responses to warming in permafrost and seasonally frozen ground hillslopes: Hydrogeology of Warming Frozen Grounds, Geophysical Research Letters, https://doi.org/10.1002/2016GL072009, http://doi.wiley.com/10.1002/ 2016GL072009, 2017.

Evans, S. G., Godsey, S. E., Rushlow, C. R., and Voss, C.: Water Tracks Enhance Water Flow Above Permafrost in Upland Arctic Alaska Hillslopes, Journal of Geophysical Research: Earth Surface, 125, https://doi.org/10.1029/2019JF005256, https://onlinelibrary.wiley.com/ doi/abs/10.1029/2019JF005256, 2020.

Frampton, A., Painter, S., Lyon, S. W., and Destouni, G.: Non-isothermal, three-phase simulations of near-surface flows in a model permafrost system under seasonal variability and climate change, Journal of Hydrology, 403, 352-359, https://doi.org/10.1016/j.jhydrol.2011.04.010, https://linkinghub.elsevier.com/retrieve/pii/S0022169411002502, 2011.

Frampton, A., Painter, S. L., and Destouni, G.: Permafrost degradation and subsurface-flow changes caused by surface warming trends, Hydrogeology Journal, 21, 271-280, https://doi.org/10.1007/s10040-012-0938-z, http://link.springer.com/10.1007/s10040-012-0938-z, 2013. 
https://doi.org/10.5194/tc-2021-60

Preprint. Discussion started: 7 April 2021

(c) Author(s) 2021. CC BY 4.0 License.

(c) (i)

Frauenfeld, O. W., Zhang, T., Barry, R. G., and GilichinskySoil, D.: Interdecadal changes in seasonal freeze and thaw depths in Russia, Journal of Geophysical Research, 109, D05 101, https://doi.org/10.1029/2003JD004245, http://doi.wiley.com/10.1029/2003JD004245, 2004.

Førland, E. J. and Hanssen-Bauer, I.: Increased Precipitation in the Norwegian Arctic: True or False?, Climatic Change, 46, 485-509, https://doi.org/10.1023/A:1005613304674, http://link.springer.com/10.1023/A:1005613304674, 2000.

Hanssen-Bauer, I., Førland, E., Hisdal, H., Mayer, S., Sand $\varnothing$, A., and Sorteberg, A.: Climate in Svalbard 2100 - a knowledge base for climate adaptation, Tech. Rep. 1/2019, Norwegian Centre for Climate Services, 2018.

Hugelius, G., Strauss, J., Zubrzycki, S., Harden, J. W., Schuur, E. A. G., Ping, C.-L., Schirrmeister, L., Grosse, G., Michaelson, G. J., Koven, C. D., O\&amp;apos;Donnell, J. A., Elberling, B., Mishra, U., Camill, P., Yu, Z., Palmtag, J., and Kuhry, P.: Estimated stocks of circumpolar permafrost carbon with quantified uncertainty ranges and identified data gaps, Biogeosciences, 11, 6573-6593, https://doi.org/10.5194/bg11-6573-2014, https://www.biogeosciences.net/11/6573/2014/, 2014.

Iijima, Y., Fedorov, A. N., Park, H., Suzuki, K., Yabuki, H., Maximov, T. C., and Ohata, T.: Abrupt increases in soil temperatures following increased precipitation in a permafrost region, central Lena River basin, Russia, Permafrost and Periglacial Processes, 21, 30-41, https://doi.org/10.1002/ppp.662, http://doi.wiley.com/10.1002/ppp.662, 2010.

Isaksen, K., Sollid, J. L., Holmlund, P., and Harris, C.: Recent warming of mountain permafrost in Svalbard and Scandinavia, Journal of Geophysical Research, 112, F02S04, https://doi.org/10.1029/2006JF000522, http://doi.wiley.com/10.1029/2006JF000522, 2007.

Jafarov, E. E., Coon, E. T., Harp, D. R., Wilson, C. J., Painter, S. L., Atchley, A. L., and Romanovsky, V. E.: Modeling the role of preferential snow accumulation in through talik development and hillslope groundwater flow in a transitional permafrost landscape, Environmental Research Letters, 13, 105 006, https://doi.org/10.1088/1748-9326/aadd30, http://stacks.iop.org/1748-9326/13/i=10/a=105006?key=crossref. ea8d38a9a41cbb120144acdd5d1d4d37, 2018.

Kane, D. L., Hinkel, K. M., Goering, D. J., Hinzman, L. D., and Outcalt, S. I.: Non-conductive heat transfer associated with frozen soils, Global and Planetary Change, 29, 275-292, https://doi.org/10.1016/S0921-8181(01)00095-9, https://linkinghub.elsevier.com/retrieve/pii/ S0921818101000959, 2001.

545 Karra, S., Painter, S. L., and Lichtner, P. C.: Three-phase numerical model for subsurface hydrology in permafrost-affected regions (PFLOTRAN-ICE v1.0), The Cryosphere, 8, 1935-1950, https://doi.org/10.5194/tc-8-1935-2014, https://www.the-cryosphere.net/8/1935/ 2014/, 2014.

Koven, C. D., Ringeval, B., Friedlingstein, P., Ciais, P., Cadule, P., Khvorostyanov, D., Krinner, G., and Tarnocai, C.: Permafrost carbon-climate feedbacks accelerate global warming, Proceedings of the National Academy of Sciences, 108, 14769-14774, https://doi.org/10.1073/pnas.1103910108, http://www.pnas.org/cgi/doi/10.1073/pnas.1103910108, 2011.

Kurylyk, B. L., Hayashi, M., Quinton, W. L., McKenzie, J. M., and Voss, C. I.: Influence of vertical and lateral heat transfer on permafrost thaw, peatland landscape transition, and groundwater flow: Permafrost thaw, landscape change and groundwater flow, Water Resources Research, 52, 1286-1305, https://doi.org/10.1002/2015WR018057, http://doi.wiley.com/10.1002/2015WR018057, 2016.

Langford, J. E., Schincariol, R. A., Nagare, R. M., Quinton, W. L., and Mohammed, A. A.: Transient and Transition Factors in Modeling Permafrost Thaw and Groundwater Flow, Groundwater, 58, 258-268, https://doi.org/10.1111/gwat.12903, https://onlinelibrary.wiley.com/ doi/abs/10.1111/gwat.12903, 2020.

Li, D.-s., Wen, Z., Cheng, Q.-g., Xing, A.-g., Zhang, M.-1., and Li, A.-y.: Thermal dynamics of the permafrost active layer under increased precipitation at the Qinghai-Tibet Plateau, Journal of Mountain Science, 16, 309-322, https://doi.org/10.1007/s11629-018-5153-5, http: //link.springer.com/10.1007/s11629-018-5153-5, 2019. 
https://doi.org/10.5194/tc-2021-60

Preprint. Discussion started: 7 April 2021

(c) Author(s) 2021. CC BY 4.0 License.

(c) (i)

Loranty, M. M., Abbott, B. W., Blok, D., Douglas, T. A., Epstein, H. E., Forbes, B. C., Jones, B. M., Kholodov, A. L., Kropp, H., Malhotra, A., Mamet, S. D., Myers-Smith, I. H., Natali, S. M., O’Donnell, J. A., Phoenix, G. K., Rocha, A. V., Sonnentag, O., Tape, K. D., and Walker, D. A.: Reviews and syntheses: Changing ecosystem influences on soil thermal regimes in northern high-latitude permafrost regions, Biogeosciences, 15, 5287-5313, https://doi.org/10.5194/bg-15-5287-2018, https://bg.copernicus.org/articles/15/5287/2018/, 2018.

Luo, D., Jin, H., Bense, V. F., Jin, X., and Li, X.: Hydrothermal processes of near-surface warm permafrost in response to strong precipitation events in the Headwater Area of the Yellow River, Tibetan Plateau, Geoderma, 376, 114531, https://doi.org/10.1016/j.geoderma.2020.114531, https://linkinghub.elsevier.com/retrieve/pii/S0016706120306704, 2020.

McGuire, A. D., Anderson, L. G., Christensen, T. R., Dallimore, S., Guo, L., Hayes, D. J., Heimann, M., Lorenson, T. D., Macdonald, R. W., and Roulet, N.: Sensitivity of the carbon cycle in the Arctic to climate change, Ecological Monographs, 79, 523-555, https://doi.org/10.1890/08-2025.1, http://doi.wiley.com/10.1890/08-2025.1, 2009.

McKenzie, J. M., Kurylyk, B. L., Walvoord, M. A., Bense, V. F., Fortier, D., Spence, C., and Grenier, C.: Invited perspective: What lies beneath a changing Arctic?, The Cryosphere, 15, 479-484, https://doi.org/10.5194/tc-15-479-2021, https://tc.copernicus.org/articles/15/ 479/2021/, 2021.

Mekonnen, Z. A., Riley, W. J., Grant, R. F., and Romanovsky, V. E.: Changes in precipitation and air temperature contribute comparably to permafrost degradation in a warmer climate, Environmental Research Letters, 16, 024 008, https://doi.org/10.1088/1748-9326/abc444, https://iopscience.iop.org/article/10.1088/1748-9326/abc444, 2021.

Painter, S. L.: Three-phase numerical model of water migration in partially frozen geological media: model formulation, validation, and applications, Computational Geosciences, 15, 69-85, https://doi.org/10.1007/s10596-010-9197-z, http://link.springer.com/10.1007/ s10596-010-9197-z, 2011.

Painter, S. L. and Karra, S.: Constitutive Model for Unfrozen Water Content in Subfreezing Unsaturated Soils, Vadose Zone Journal, 13, vzj2013.04.0071, https://doi.org/10.2136/vzj2013.04.0071, http://doi.wiley.com/10.2136/vzj2013.04.0071, 2014.

Painter, S. L., Coon, E. T., Atchley, A. L., Berndt, M., Garimella, R., Moulton, J. D., Svyatskiy, D., and Wilson, C. J.: Integrated surface/subsurface permafrost thermal hydrology: Model formulation and proof-of-concept simulations, Water Resources Research, 52, 6062-6077, https://doi.org/10.1002/2015WR018427, http://doi.wiley.com/10.1002/2015WR018427, 2016.

Porter, C., Morin, P., Howat, I., Noh, M.-J., Bates, B., Peterman, K., Keesey, S., Schlenk, M., Gardiner, J., Tomko, K., Willis, M., Kelleher, C., Cloutier, M., Husby, E., Foga, S., Nakamura, H., Platson, M., Wethington, M., Williamson, C., Bauer, G., Enos, J., Arnold, G., Kramer, W., Becker, P., Doshi, A., D’Souza, C., Cummens, P., Laurier, F., and Bojesen, M.: ArcticDEM, https://doi.org/10.7910/dvn/ohhukh, https://dataverse.harvard.edu/citation?persistentId=doi:10.7910/DVN/OHHUKH, type: dataset, 2018

Riseborough, D., Shiklomanov, N., Etzelmüller, B., Gruber, S., and Marchenko, S.: Recent advances in permafrost modelling, Permafrost and Periglacial Processes, 19, 137-156, https://doi.org/10.1002/ppp.615, http://doi.wiley.com/10.1002/ppp.615, 2008.

Schuh, C., Frampton, A., and Christiansen, H. H.: Soil moisture redistribution and its effect on inter-annual active layer temperature and thickness variations in a dry loess terrace in Adventdalen, Svalbard, The Cryosphere, 11, 635-651, https://doi.org/10.5194/tc-11-6352017, https://www.the-cryosphere.net/11/635/2017/, 2017.

Schuur, E. A. G., McGuire, A. D., Schädel, C., Grosse, G., Harden, J. W., Hayes, D. J., Hugelius, G., Koven, C. D., Kuhry, P., Lawrence, D. M., Natali, S. M., Olefeldt, D., Romanovsky, V. E., Schaefer, K., Turetsky, M. R., Treat, C. C., and Vonk, J. E.: Climate change and the permafrost carbon feedback, Nature, 520, 171-179, https://doi.org/10.1038/nature14338, http://www.nature.com/articles/nature14338, 2015 . 
https://doi.org/10.5194/tc-2021-60

Preprint. Discussion started: 7 April 2021

(c) Author(s) 2021. CC BY 4.0 License.

(c) (i)

Shojae Ghias, M., Therrien, R., Molson, J., and Lemieux, J.-M.: Numerical simulations of shallow groundwater flow and heat transport in continuous permafrost setting under impact of climate warming, Canadian Geotechnical Journal, 56, 436-448, https://doi.org/10.1139/cgj2017-0182, http://www.nrcresearchpress.com/doi/10.1139/cgj-2017-0182, 2019.

Sjöberg, Y., Coon, E., K. Sannel, A. B., Pannetier, R., Harp, D., Frampton, A., Painter, S. L., and Lyon, S. W.: Thermal effects of groundwater flow through subarctic fens: A case study based on field observations and numerical modeling, Water Resources Research, 52, 1591-1606, https://doi.org/10.1002/2015WR017571, http://doi.wiley.com/10.1002/2015WR017571, 2016.

Strand, S. M., Christiansen, H. H., Johansson, M., Åkerman, J., and Humlum, O.: Active layer thickening and controls on interannual variability in the Nordic Arctic compared to the circum-Arctic, Permafrost and Periglacial Processes, p. ppp.2088, https://doi.org/10.1002/ppp.2088, https://onlinelibrary.wiley.com/doi/10.1002/ppp.2088, 2020.

Veuille, S., Fortier, D., Verpaelst, M., and Grandmont, K.: Heat Advection in the Active Layer of Permafrost: Physical Modelling to Quantify the Impact of Subsurface Flow on Soil Thawing., in: GéoQuébec 2015 Proceedings of the 68th Canadian Geotechnical Conference and the 7th Canadian Permafrost Conference, p. 9, Québec City, Québec, 2015.

Walvoord, M. A. and Kurylyk, B. L.: Hydrologic Impacts of Thawing Permafrost-A Review, Vadose Zone Journal, 15, 0, https://doi.org/10.2136/vzj2016.01.0010, https://dl.sciencesocieties.org/publications/vzj/abstracts/15/6/vzj2016.01.0010, 2016.

Wen, Z., Niu, F., Yu, Q., Wang, D., Feng, W., and Zheng, J.: The role of rainfall in the thermal-moisture dynamics of the active layer at Beiluhe of Qinghai-Tibetan plateau, Environmental Earth Sciences, 71, 1195-1204, https://doi.org/10.1007/s12665-013-2523-8, http: //link.springer.com/10.1007/s12665-013-2523-8, 2014.

Westermann, S., Langer, M., Boike, J., Heikenfeld, M., Peter, M., Etzelmüller, B., and Krinner, G.: Simulating the thermal regime and thaw processes of ice-rich permafrost ground with the land-surface model CryoGrid 3, Geoscientific Model Development, 9, 523-546, https://doi.org/10.5194/gmd-9-523-2016, https://gmd.copernicus.org/articles/9/523/2016/, 2016.

Wu, Q. and Zhang, T.: Recent permafrost warming on the Qinghai-Tibetan Plateau, Journal of Geophysical Research, 113, D13 108, https://doi.org/10.1029/2007JD009539, http://doi.wiley.com/10.1029/2007JD009539, 2008.

Zhang, T., Osterkamp, T. E., and Stamnes, K.: Effects of Climate on the Active Layer and Permafrost on the North Slope of Alaska, U.S.A., Permafrost and Periglacial Processes, 8, 23, 1997.

Zhang, T., Barry, R. G., Knowles, K., Heginbottom, J. A., and Brown, J.: Statistics and characteristics of permafrost and ground-ice distribution in the Northern Hemisphere ${ }^{1}$, Polar Geography, 23, 132-154, https://doi.org/10.1080/10889379909377670, http://www.tandfonline. com/doi/abs/10.1080/10889379909377670, 1999.

Zhu, X., Wu, T., Li, R., Xie, C., Hu, G., Qin, Y., Wang, W., Hao, J., Yang, S., Ni, J., and Yang, C.: Impacts of Summer Extreme Precipitation Events on the Hydrothermal Dynamics of the Active Layer in the Tanggula Permafrost Region on the QinghaiTibetan Plateau: Impacts of Precipitation on Active Layer, Journal of Geophysical Research: Atmospheres, 122, 11,549-11,567, https://doi.org/10.1002/2017JD026736, http://doi.wiley.com/10.1002/2017JD026736, 2017. 